\title{
A CONTRASTIVE STUDY OF APOLOGIES PERFORMED BY GREEK NATIVE SPEAKERS AND ENGLISH LEARNERS OF GREEK AS A FOREIGN LANGUAGE
}

\author{
Spyridoula Bella
}

\begin{abstract}
This paper investigates apologies produced by Greek native speakers and English learners of Greek as a foreign language in two informal $(-\mathrm{P},-\mathrm{D})$ and two formal situations $(+\mathrm{P},+\mathrm{D})$. Drawing on data elicited by means of an assessment questionnaire, a DCT and the participants' verbal reports, the study attempts to explore the extent to which the two groups differ in their contextual assessments of the apology situations under examination and in strategy use. The results indicated that the learners of the study differed significantly from the native speakers in regard to their assessments of the contextual parameters (power, distance, severity of offence) involved in each apology situation. Furthermore, significant quantitative and qualitative differences were attested in relation of the two groups' preferences in strategy use when performing apologies in Greek. On the basis of these results it is argued, that these learners interlanguage apology behavior is influenced both by their native cultural values and (negative) politeness orientation, as well as from lack of adequate socio-pragmatic development resulting mainly from their foreign language learner status.
\end{abstract}

Keywords: Apology; Discourse completion test; Greek; Interlanguage; Politeness.

\section{Introduction}

The acquisition of pragmatic competence, i.e. the learners' ability to "employ different linguistic formulae in an appropriate way when interacting in a particular social and cultural context" (Usó-Juan \& Martínez-Flor 2008: 349), has been a major pursuit of second language learning and teaching in the past few decades. Pragmatic competence is made up by two fundamental components: pragmalinguistic knowledge, which refers to knowledge of the particular linguistic resources for formulating a speech act, and sociopragmatic knowledge, i.e. knowledge of the contextual and social variables (status, social distance, etc.) which determine the appropriateness of the pragmalinguistic choice (see Kasper 1997: 115-116; Thomas 1983; Usó-Juan 2010: 237). Therefore, becoming pragmatically competent is understood as "the process of establishing sociopragmatic and pragmalinguistic competence and the increasing ability to understand and produce sociopragmatic meanings with pragmalinguistic conventions" (Kasper \& Roever 2005: 318).

Against this backdrop, the non-native speakers' ability to comprehend and produce various speech acts, as well as the linguistic means that they employ in order to 
modify the illocutionary force and attenuate potential face-threats of their speech acts, have been of focal interest in the field of interlanguage pragmatics. Of even more interest, has been the question of the ways in which these means deviate from the ones used by native speakers.

Among the numerous studies that have been undertaken to date into a variety of speech acts, apologies hold a rather prominent place. Apologizing is an act that is usually performed when assumed social norms have been violated through a real or potential offence in order for social harmony to be restored ${ }^{1}$. They are considered particularly challenging both due to their universal nature, since they are probably found in most if not all all human communities (cf. Farashayian 2011: 224), and to their complexity, since they can be composed of one or several strategies and involve multiple threats to the interlocutors' face (cf. Flores Salgado 2011: 16). Therefore, apologies are closely related with matters of politeness and facework and have often been studied under the rubric of Brown and Levinson's (1987) politeness model.

A considerable body of pragmatic research has investigated apologies in different languages and cultures, focusing on various variables such as the politeness strategies employed (e.g. Brown \& Levinson 1987; García 1989; Ogiermann 2009), the factors affecting the choice of particular strategies (e.g. Cohen \& Olshtain 1981; Fraser 1981; Olshtain 1989; Olshtain \& Cohen 1983), the cultural values reflected in apology realization (e.g. Bataineh \& Bataineh 2006; Cordella 1990; Suszczyńska 1999; Ogiermann 2009) and the strategies employed by native and non-native speakers (e.g. García 1989; Shardakova 2005; Trosborg 1987; Flores Salgado 2011).

The present paper aims to contribute to this latter aspect of research by examining apologies performed by English learners of Greek as a foreign language. ${ }^{2}$ This choice was triggered by three factors: First, no research has been conducted so far on Greek interlanguage apologies. Therefore, this study aims to bridge this gap, at least partially, and to contribute to the body of cross-linguistic research findings. Second, besides the difficulties stated above in regard to the comprehension and production of apologies by non-native speakers in general, foreign language learners seem to be at an additional disadvantage, due to the rather limited authentic target-language input that they are exposed to (Bardovi-Harlig \& Dörnyei 1999; Bella 2012; Martínez-Flor \& Usó-Juan 2006). Third, the apology performance of English learners of Greek can be of particular interest, due to the well documented difference in the politeness orientations of the two societies. That is, while English society has been found to prefer negative politeness strategies (Brown \& Levinson 1987), Greeks have been documented to prefer positive politeness ones (see e.g. Antonopoulou and Sifianou 2003; Bella 2009, 2011, 2012; Makri-Tsilipakou 2001; Pavlidou 1994; Sifianou 1992).

The paper begins with a discussion of apologies and proceeds to review previous research on interlanguage apologies. Section 3 presents the method of the study, whereas section 4 highlights the main findings. The results are discussed in section 5 in the light of the relevant literature. Finally, Section 6 sums up the conclusions of the study.

\footnotetext{
${ }^{1}$ Anticipatory apologies that occur prior to the offensive act are beyond the scope of the present study.

${ }^{2}$ Any reference to 'English learners of Greek' in the present study, involves solely native English speakers from England (and not other English speaking communities).
} 


\section{Theoretical background}

\subsection{Apologies}

Apologies fall into the category of expressive illocutionary acts and have been defined as transactions involving "a bid to change the balance sheet of the relation between $S$ and H" (Leech 1983: 125). That is, apologies constitute attempts to restore the imbalance created in the relationship of the interlocutors by $\mathrm{S}$ committing an offence adversely affecting $\mathrm{H}$. Therefore, apologies are considered remedial interchanges aiming to restore and maintain social equilibrium, since they allow "the participants to go on their way, if not with satisfaction that matters are closed, then at least with the right to act as if they feel that matters are closed and that ritual equilibrium has been restored" (Goffman 1971: 140). This remedial nature highlights the social character of apologizing and links it to issues of face-threat and face-preservation. ${ }^{3}$ Against this backdrop, Brown and Levinson (1987: 187) classify apologies as negative politeness strategies, aiming at protecting the negative face of the addressee whose rights, property or freedom of action have been threatened or violated by the offensive act. Moreover, they (1987: 68) consider apologies threatening the speaker's positive aspect of face, since apologizing involves the speaker's admission that he/she is at fault for an offence he/she regrets.

Brown and Levinson's conception of apologies has been criticized both for viewing them as strictly face-threatening for the speaker and face-supporting for the addressee, as well as for ignoring the other aspects of the interlocutors' face (see e.g. Deuthschmann 2003; Edmondson \& House 1981; House \& Kasper 1981; Meier 1992; Ogiermann 2009; Symeon 2000). As Deutschmann (2003: 39) contends, when analyzing apologies "both negative and positive face needs should be taken into account" and "these should be viewed from both hearer and speaker perspectives". An apology should always be viewed as a reaction triggered by an offence and it is in the context of pairing specific offences with specific apologies that any elements of facethreat or face-preservation should be analyzed. Offences are threatening both the positive and the negative face of the victim, since she/he may feel that her/his personality is not being respected and that "the feelings of solidarity, co-operation and trust held [between herself/himself and the offender] are no longer obvious" (Symeon 2000: 87). With respect to the offender's face needs, it can be claimed that the offence has damaged her/his positive face endangering her/his image as a likeable and reliable member of the group. Finally, the negative aspect of her/his face is also harmed, "since the burden of the offensive act prevents her/him from acting freely and communicating openly until her/his good reputation has been restored" (Symeon 2000: 87). Therefore, apologies are considered multidirectional acts, in the sense that can attend to both aspects of both interlocutors' face.

Yet, I will side with Ogiermann (2009), who views the apologizer's positive face needs as central to all apologies (see also Edmondson \& House 1981; Fraser 1981; Meier 1992), since what damages the offender's positive face is not the apology, but the offence. The apology is the act that attempts to restore it. Therefore, "while damage to

\footnotetext{
${ }^{3}$ According to Owen (1983: 22), remedial interchanges are taken to comprise those acts "concerned specifically with repairing damage to face, where face-preservation itself becomes the object of the conversation for a time however short".
} 
the hearer's positive face as well as negative face can necessitate it, without the speaker's positive face needs, there might be no apology, which is uttered despite threat to negative face. " (Ogiermann 2009: 55)

According to Olshtain \& Cohen (1983) there are six strategies which can make up an apology irrespective of politeness orientation and other culturally specific issues: explicit use of an illocutionary force indicating device (IFID), an explanation or account for the offence, an offer of repair, a promise of forbearance ${ }^{4}$ and an expression of concern for the offended. Due to the different levels of severity of the offences that call for an apology, it was noted by Blum-Kulka et al. (1989) that different forms of apology intensification may be employed. These can be of two main types: a) internal intensifiers that are included in the IFID and b) external ones, such as expressing concern for the hearer. It is also widely acknowledged that not all of these strategies occur in an apology at the same time and that their selection and combinations depend on various factors, such as the severity of the offence and the degrees of power and social distance existing between interlocutors (see e.g. Olshtain \& Cohen 1989; Ogiermann 2009; Symeon 2000). The above strategies will be further analyzed and exemplified in section 3. The next section will focus on the main findings of the research on non-native apologies.

\subsection{Interlanguage apologies: Literature review}

The vast body of research on apologies to date has been of a cross-cultural nature, comparing their realizations in two or more languages. Although this research is beyond the scope of the present study which focuses on interlanguage apologies, a brief mention will be made here of the only study that has compared L1 Greek and English apologies, since its findings are particularly relevant to the purposes of the present research. This study was conducted by Symeon (2000) who used data from a variety of sources including Discourse Completion Tests (DCTs), English and Greek plays and naturally occurring discourse, in order to examine the similarities and differences in the realization of apologies in the two linguistic communities. Although Symeon's study examined apologies within Brown and Levinson's framework of politeness, her approach differed from theirs in that, unlike Brown and Levinson who classify apologies as negative politeness strategies employed to protect the negative face of the offended party, she considered them as affecting all other aspects of both interlocutors' face, thus highlighting their multidirectional character. Not surprisingly, Symeon's main finding was that the politeness orientations of the two communities (English and Greek) do in fact affect the realization of apologies. That is, Greeks were found to show a marked preference for positive politeness apology strategies, whereas English speakers opted for negative politeness ones. Furthermore, Symeon found that several strategies, such as expressions of regret, self-accusation and reasons for the offence exhibited greater frequencies in the Greek data, whereas strategies like IFIDs and expressions of lack of intent were considerably more frequent in the English data. In addition, Symeon

${ }^{4}$ This is the term employed in the relevant literature for the strategy involving the speaker's promise that the offensive act will not occur again. However, for reasons I explain in the coding section (3.2.2.), in this study the term 'promise of desistance' will be used to refer to this particular strategy.

5 For thorough reviews of such studies, see Flores Salgado (2011); Marquez Reiter (2000); Ogiermann (2009). 
noted that neither of the two groups of speakers used one type of politeness strategies (positive or negative) exclusively. However, it turned out that when the speakers' contributions included both negative and positive politeness strategies, the latter tended to precede the former in the Greek data, whereas in the case of the English data, this pattern was reversed. Due to the multiple data sources and the painstaking analysis of the data, Symeon's (2000) findings is a valuable reference point for the investigation of apologies in the present study.

Turning now to interlanguage apologies which are my particular concern here, in the rest of this section I will focus on some of the most influential interlanguage apology research to date in order to highlight the main issues raised in regard to NNSs' apology performance and contextual assessments. The main focus is on single-moment studies. Nevertheless, some of the most important developmental studies will also be discussed, since their findings can be particularly enlightening for the present purposes. The section closes with a summary of the main research findings.

In an attempt to develop a measure of sociocultural competence, focusing on the act of apologizing, Cohen \& Olshtain (1981) conducted a study that compared the apologetic behavior of English NSs, Israeli NSs of Hebrew and Israeli learners of English. The data were elicited by means of role-plays of eight different situations. The analysis revealed several instances of negative pragmatic transfer in the learners' performance, especially in regard to appropriate intensity of regret. Additionally, some of the learners' responses seemed to indicate a deficiency in linguistic proficiency, since they failed to include some of the strategies found in native English and native Hebrew responses.

Using the same apology situations Olshtain (1983) examined the apologetic behavior of Russian and English learners of Hebrew in Israel. In addition to the data collection, Olshtain conducted interviews with the participants in order to establish their perception of apology as language-specific or language-universal. The analysis showed that English learners tended to apologize less in Hebrew than in their native language, consistent with their perception about Hebrew, while Russian learners apologized more in Hebrew than they did in Russian, again consistent with their perceptions about Hebrew. It was thus concluded that the performance of adult learners may be strongly influenced by their stereotypical conceptions of what is appropriate in the target language.

House (1989) examined the production of apologies by NSs of English, NSs of German and German learners of English using a DCT combined with 3-point rating scales that aimed to assess the weight of context-external and context-internal factors in the situations under examination (distance, dominance, addressee's expectation of an apology, offender's obligation to apologize and impositions involved in the apology). With the exception of imposition, which received higher ratings from the German than from the English native speakers, the ratings were found to be similar between the two NSs groups. However, it was observed that in contrast to native speakers that preferred other-oriented strategies (e.g. expressions of interest in the interlocutor's state or demonstrations of concern for the offended), the learners preferred self-oriented strategies (e.g., denials of intent to commit offensive acts or references to selfdeficiencies).

García (1989) also examined NNSs' apologetic behavior by means of role-plays enacted by Venezuelan Spanish NNSs and compared to those of American English NSs. 
Her study focused on one situation in which a guest must apologize to a host for not attending his party. It was shown that Venezuelan NNSs, consistent with their L1 politeness orientation, opted for a positive politeness approach employing more apologies and confrontational devices than the American NSs. This type of negative transfer was at odds with the (negative) politeness expectations of the American NSs and, therefore, it was found to result in miscommunication and disharmony.

Using a 20-item DCT, Bergman \& Kasper (1993) investigated the apology performance of Thai NNSs of English in comparison with Thai and American English native speakers. Besides the actual DCT, a metapragmatic assessment questionnaire was administered to examine the subjects' perceptions of a variety of context-internal and context-external factors involved in the offence situations described in the DCT. In relation to the context internal factors, a high correlation was observed between severity of offence, on the one hand, and obligation to apologize and offender's face loss, on the other. In contrast, no correlation was observed between context internal factors, such as dominance and distance, and context external factors. The assessment results were perceived as providing support to Olshtain's (1989: 60) hypothesis that "severity of offence is the representative factor in the sociopragmatic set of apology". Among the different strategies employed by the participants, the only one that appeared to correlate with context-internal factors in all three groups was apology intensification. Furthermore, the NSSs were found to use higher frequencies of strategies like repair, downgrading responsibility and other types of redress, confirming previous findings according to which learners typically use more words than native speakers in accomplishing similar pragmatic goals ( Blum-Kulka \& Olshtain 1986; Edmondson \& House 1981; House 1989).

Turning now to developmental studies, one of the earliest and most influential studies with regard to the development of language learners' apologetic behavior is Trosborg's (1987). Using role-plays within which participant roles varied along the parameters of social distance and dominance, Trosborg compared the apology strategies used by English native speakers and three groups of Danish learners of English of different proficiency levels (beginner, intermediate, advanced). The analysis showed that all learner groups employed fewer explanations and minimizing strategies and tended to use more direct apologies and denial of responsibility. These findings were attributed mainly to insufficient linguistic knowledge. What was found to really develop with proficiency was the use of modality markers, with the more advanced learners employing them more frequently, increasing thus the politeness level of their apologies.

In a later study of similar design, Trosborg (1995) further confirmed that all three learner groups used a higher number of IFIDs (direct apologies) and resorted mainly to the use of I am sorry. According to the researcher this behavior did not result from L1 transfer but mainly from the learners' "overlearning" this particular formula (1995: 406). Moreover, the NSs' data displayed significantly greater frequencies of apology intensification than the learners', a finding that was attributed to the learners' lack of adequate linguistic means. Nevertheless, her findings showed a positive correlation between intensification frequency and increasing proficiency.

In line with Bergman and Kasper (1993), Maeshiba et al. (1996) focused on pragmatic transfer and whether it was influenced more strongly by contextual factors or by the learners' proficiency level. The participants were two groups of Japanese learners of English (intermediate and advanced) whose apologies were compared to those of two groups of native speakers (English and Japanese). The results showed that the 
intermediate group transferred their apology behavior from Japanese to English more than the advanced group. Therefore, the results of this study contradict Takahashi and Beebe's (1987) findings that advanced learners' performance tends to exhibit more instances of negative pragmatic transfer.

In a more recent study, Shardakova (2005) examined by means of a DCT and a contextual assessment questionnaire the production and contextual assessments of apologies of American learners of Russian studying in a Russian University. The learners' acquisition of pragmalinguistic and sociolinguistic knowledge was investigated in relation to both their advancement in linguistic proficiency and study abroad experience. The findings showed that contrary to the Russian NSs that opted for distinctly different means depending on the contextual parameters of each apology situation, the learners tended to overgeneralize their apologies to intimates and carry them over to other communicative contexts (unfamiliarity or unequal social status). It was also found that the most decisive factor leading to near-native apologetic behavior was not linguistic proficiency, but the degree of exposure to the target language. Moreover, it was observed that, when not combined with exposure, advancement in linguistic proficiency could lead to strategy overuse and overly polite behavior.

Dalmau \& Godor (2007) conducted another cross-sectional study aiming to analyze the apology realization of Catalan learners of English at three different proficiency levels in response to a DCT. The learners were found to have access to the same range of apology strategies irrespective of their proficiency level. Although it was found that the increase of L2 proficiency brought with it an overall decrease in pragmalinguistic non-L2-like performance, as well as an increase in the use of more target-like apology intensification, the latter was found to lag behind NSs' intensification even in the case of advanced learners. Moreover, the study confirmed Takahashi and Beebe's claim (1987) that native-like command triggers an increase in negative pragmatic transfer.

Finally, in a very recent study, Flores Salgado (2011) examined the development of apologies (and requests) in the interlanguage of Mexican learners of English of three different proficiency levels (basic, intermediate, advanced). In regard to apologies it was shown that participants of all proficiency levels used less apology strategies overall than American English native speakers. Instances of negative transfer were also attested in the advanced level participants' production. These learners were found to often transliterate Spanish apology formulas in their expression of apologies in English. Moreover, a positive correlation was attested between level of proficiency and intensification.

To sum up, previous research on interlanguage apology realization has revealed the following (cf. Bataineh \& Bataineh 2006: 1906):

1. Despite the similarities in the realization patterns of apologies detected across cultures, several strategies are culture-specific.

2. L2 learners tend to transfer their native sociopragmatic strategies to their L2 apology performance.

3. The choice of apology strategies is often affected by social/situational parameters.

4. Advanced level of proficiency does not guarantee native-like apology performance.

In the light of the above, the research questions of the present study are the following: 
1. What are the differences exhibited between the two groups under examination in regard to apology strategy use?

2. To what extent do the two groups' assessments of the contextual parameters of the apology situations differ?

4. To what extent are differences in contextual assessments and politeness orientations reflected in the two groups' data and how do they affect the learners' interlanguage?

The analysis of the participants' performance will rely on Brown and Levinson's (1987) theory of politeness, since, despite valid or invalid criticisms, it seems to account adequately for the present data, not least because Brown and Levinson's "astute description of linguistic strategies is useful when analyzing linguistic interaction" (Locher 2006: 250) and it "still has a great deal of analytical mileage in that it provides a framework for understanding social behavior" (Christie 2005: 6).

\section{Method}

\subsection{Participants}

A total of 70 subjects participated in the study: 35 native speakers of Greek (17 males and 18 females), all coming from Athens (mean age: 23.7 years), and 35 (20 males and 15 females) English learners of Greek as a foreign language (mean age: 22.8 years).

The native speakers of Greek (GNS) were all undergraduate (BA) and postgraduate (MA) students at the University of Athens. The English learners had just arrived in Athens at the time of the study (academic year 2010-11) and belonged to two different categories: a) learners that were going to attend the six-week language courses offered by the University of Athens (Program of Summer Scholarships for Greek Studies), and b) learners that took Greek courses at the University of Athens' Centre for Teaching Greek as a Second/Foreign Language while attending a Socrates/Erasmus Program. All learners (GFL) were undergraduate students whose previous training in Greek had taken place in England, i.e. they were learners of Greek as a foreign language. All learners were of an advanced level according to the results of the placement test they took at the beginning of their courses. This test was designed following the guidelines of the Common European Framework for the Teaching and Assessment of Languages (CEF) (2001) and included grammar, reading, writing and listening components. Along these lines, the competence of these learners corresponded roughly to the $\mathrm{C} 1$ level, ${ }^{6}$ as described in the CEF (p.24). None of the learners had spent any amount of time in Greece prior to the time of the research.

\footnotetext{
${ }^{6}$ Effective operational proficiency or advanced level.
} 


\subsection{Instruments and procedures}

\subsubsection{DCT, assessment questionnaire and verbal reports}

The main instrument for data collection was a DCT (see Blum-Kulka et al. 1989) designed to elicit speech acts in ten different situations, four of which were designed to elicit apologies. The other six situations were aimed to function as distractors: two situations designed to elicit requests, two designed to elicit suggestions and two to elicit request refusals. For the present purposes, I analyzed the production of the studies in the four the apology situations: In the first situation, the subject has been late for an appointment with a friend, while in the second she/he has broken a friend's DVD player. The third and fourth situations involved offences towards a professor: In situation 3 the subject has forgotten an appointment with his/her professor, while in situation 4 she/he has damaged a book that she/he has borrowed from his/her professor. The description of the situations in the original DCT included information on the social distance (D) and relative power $(\mathrm{P})$ between the participants (see Appendix).

Thus, while the first two situations were symmetrical in the sense that they involve familiarity and no power difference $(-P,-D)$, the third and fourth ones were asymmetrical, since they involve distance and power $(+\mathrm{P},+\mathrm{D})$ (see Brown \& Levinson 1987; Scollon \& Scollon 2001: 54-57).

Although I agree with those who argue that natural data constitute the best source for analyzing interactions (see, e.g. Kasper 2000: 318, Wolfson 1981: 9), there are at least two important limitations to the benefits of ethnographic research on pragmatic strategies: first, contextual variables cannot be controlled and, second, the occurrence of a particular speech act cannot be predicted (see Gass and Houck 1999: 25; Ogiermann 2009: 67-70). Furthermore, as Kasper (2000: 320) points out, in cases that the research focuses on a particular pragmatic element, e.g. a particular speech act, "it may take an unreasonable amount of [authentic] data to obtain sufficient quantities of the pragmatic feature under study". 7

To overcome these shortcomings, an open DCT was selected as a more adequate instrument for the present research purpose, not least because as Kasper (2000: 329) contends, when designed carefully, DCTs "are useful to inform about speakers" pragmalinguistic knowledge of the strategies and linguistic forms by which communicative acts can be implemented, and about their sociopragmatic knowledge under which particular strategic and linguistic choices are appropriate". Nevertheless, data elicited by means of DCTs "can never be the same as authentic conversation" (Kasper 2000: 318). Therefore, the findings of the study should be understood in view of the fact that DCT data are brought into being for research purposes and, hence, they are subject to certain limitations the most obvious being that they "cannot be expected to precisely reflect natural speech" (Ogiermann 2009: 68).

In order to examine the learners' and native speakers' socio-pragmatic assessments of the various situational parameters an assessment questionnaire was also developed. Participants were asked for each situation to rate on a three-point scale interlocutor's relative power and distance as well as severity of offence (cf. Shardakova 2005: 431).

${ }^{7}$ For extended discussions on pragmatic research methods and their suitability to different research questions in speech act research, see Félix-Brasderer (2010); Jucker (2009); Ogiermann (2009). 
Finally, in order to overcome the DCT's limitations to a certain extent, in the present study the DCT data were supplemented with some retrospective verbal report data from the two groups' participants. As Woodfield (2010: 22) contends, the combination of such data with a written elicitation instrument "may provide insights into learners' perceptions of the sociocultural aspects of the discourse situation (social status, social distance) which learners attend to while on task".

The interviews with the participants took place immediately after the completion of the DCT. For various practical reasons, mainly time limitations, interviews were conducted with 15 native speakers and 22 learners. The researcher focused on the four situations under examination and mainly posed fixed questions guided by Ericsson \& Simon's (1993: 198) four types of statements in the verbalization process: intentions, cognitions, planning and evaluation (cf. Woodfield 2010: 9). The main questions were:

1. What did you notice about the situation?

2. How difficult did you find it to answer?

3. What were you paying attention to?

4. What were you trying to achieve by saying what you said?

5 . Were you satisfied with your answer?

Additionally, following Jourdenais's (2001: 357) instigation that researchers should avoid leading questions and instead ask "focused yet open-ended questions" some datadriven questions were added in the interviews, in order to prompt learners to elaborate on their answers. Examples of such questions included "You said situation $\mathrm{X}$ was difficult for you. Could you say more about that?", or "You said you felt your answer was 'inadequate' in situation X. Why do you say that?". Nevertheless, a couple of more close-ended questions were added in certain cases, in order for the researcher to have a better understanding of the participants' frame of mind. For instance, having observed that most of the Greek speakers avoided telling the truth about forgetting the appointment with the professor, the researcher asked the participants to justify this choice.

\subsubsection{Coding}

The categories of my classification scheme for the DCT data were based on those proposed by Olshtain \& Cohen (1983) and further developed by Blum-Kulka et al. (1989) and included the following:

1. Explicit use of an Illocutionary Force Indicating Device (IFID): formulaic forms of apology (e.g. $\sigma v \gamma \gamma \nu \omega ́ \mu \eta$ ('I am sorry' [lit. 'forgiveness']), $\mu \varepsilon \sigma v \gamma \chi \omega \rho \varepsilon i \varsigma$ ('forgive [declarative] me').

2. Intensification: various intensifying adverbials internal to the IFID (e.g. $\varepsilon \imath \lambda \imath \kappa \rho \imath v \alpha$ 'really' [lit. 'sincerely'], $\pi \circ \lambda \dot{v}$ 'very')

3. Reasons/explanations for the offence (e.g. cí $\varepsilon \pi o \lambda \dot{v} \kappa i v \eta \sigma \eta$ 'there was a lot of traffic')

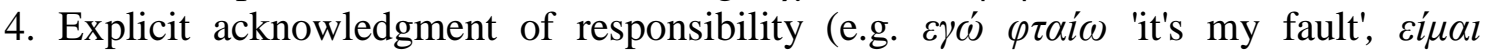

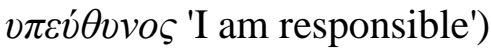

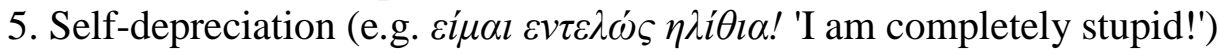

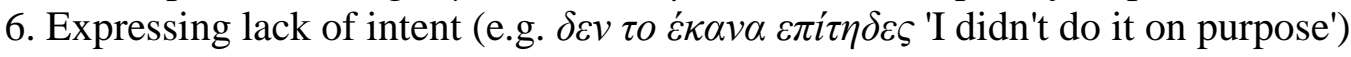




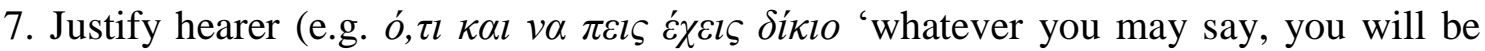
right')

8. Expression of embarrassment/regret (e.g. $v \imath \omega \dot{\theta} \theta \omega \pi \sigma \lambda \dot{\alpha} \alpha \dot{\sigma} \chi \eta \mu \alpha$ 'I feel very bad')

9. Offer of repair: speaker offers to remedy the damage inflicted upon the hearer (e.g.

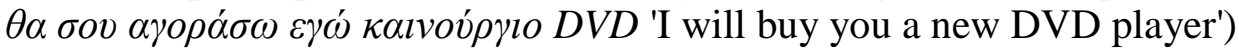

10. Promise of desistance: speaker promises that the offensive act will not occur again (e.g. $\delta \varepsilon v \theta \alpha \varepsilon \pi \alpha v \alpha \lambda \eta \varphi \theta \varepsilon i$ 'it will not happen again')

11. Humor: various humorous comments employed to pacify the hearer. ${ }^{8}$

12. Appeaser: compensatory offers not directly connected with the speaker's offence

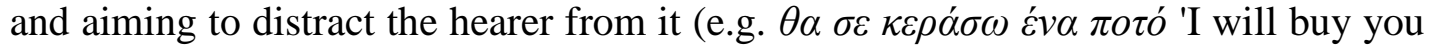
a drink)

Before proceeding with the results of the study, some clarifications are in order, in relation to the classification scheme presented above. First, in Blum-Kulka et al.'s (1989) classification, strategies 4-8 are considered substrategies of a 'Taking on responsibility' superstrategy. However, I believe that almost each and every other strategy involved in apologies can be considered an expression of responsibility acknowledgment on the part of the offender. For instance, both offers of repair and promises of desistance imply that the speaker considers herself/himself responsible for the offensive act. Therefore, I opted to treat strategies 4-8 as separate superstrategies. In addition, I opted for the term 'promise of desistance' instead of the widely used 'promise of forbearance', since 'to forbear' means 'giving up a legal right to do something' and, therefore, 'forbearance' is misleading in this context. ${ }^{9}$ Moreover, Blum-Kulka et al. (1989: 291) treat statements such as 'it's my fault' as realizations of the 'Explicit selfblame' strategy. To accommodate my data, I opted for the term 'Explicit acknowledgment of responsibility' to refer to such statements, and kept 'selfdepreciation' to refer to self-denigrating comments like 'I am completely stupid' that are particularly frequent especially in the Greek native speakers' apologies.

Second, it has to be kept in mind that, although 'Intensification' has been included in this classification scheme, this is not in fact a separate strategy, but an internal upgrader of IFIDs. Although lexical/phrasal upgraders/downgraders are beyond the scope of the present study, this particular device was incorporated in the scheme, due to its well documented importance for the expression of apologies (see e.g. Dalmau \& Gotor 2007; Mir 1992; Olshtain 1983; Trosborg 1995).

In the next section, I will present the results of the assessment questionnaire, the DCT and the learners' reports. The findings will be discussed in section 5.

\footnotetext{
${ }^{8}$ Blum-Kulka et al. (1989: 294) classify strategies 11 and 12 as means to distract the hearer from the offense.

${ }^{9}$ This is a point made by the paper's anonymous referee.
} 


\section{Results}

\subsection{Assessment results}

The two groups under examination exhibited important differences in regard to their assessment of both the severity of offence and the power/distance between interlocutors. The means of their scores are presented in Table 1.

As shown in Table 1, the Greek NSs attributed much higher severity scores to the situations involving communication with the professor (S3, S4) than the ones involving communication with a friend (S1, S2). Therefore, these speakers established a correlation between power/distance and severity assessments ${ }^{10}$. In contrast, GFL marked as more severe situations involving property damage (S2, S4), irrespective of the interlocutors' relationship and attributed lower severity scores to situations involving tardiness.

With respect to relative power and distance assessments, the only point of actual agreement between the two groups concerned the lack of power differences between friends. As indicated in Table 1, both groups' scores were equally low in this respect. The most impressive difference concerned the two groups' judgments in relation to the power/distance relationship between students and professors. Specifically, Greeks were found to attribute much higher scores to the situations involving communication with the professor than GFL. Although the latter marked these situations as involving more power and distance than the ones with friends, their scores were considerably lower than those of the GNS. Nevertheless, the learners were shown to consider friends as more distant than NSs did.

Table 1: Assessment of contextual parameters by the two groups' participants in the four situations

\begin{tabular}{|c|c|c|c|c|c|c|c|c|}
\hline \multirow{3}{*}{$\begin{array}{l}\text { Contextual } \\
\text { parameters }\end{array}$} & \multicolumn{8}{|c|}{ Situations } \\
\hline & \multicolumn{2}{|c|}{ S1 (-P,-D) } & \multicolumn{2}{|c|}{ S2 (-P,-D) } & \multicolumn{2}{|c|}{$\mathrm{S3}(+\mathrm{P},+\mathrm{D})$} & \multicolumn{2}{|c|}{$\mathrm{S} 4(+\mathrm{P},+\mathrm{D})$} \\
\hline & M & SD & M & SD & M & SD & M & SD \\
\hline GNS & 1.2 & 0.47 & 1.49 & 0.56 & 2.74 & 0.4 & 2.91 & 0.28 \\
\hline GFL & 1.8 & 0.43 & 2.34 & 0.68 & 1.89 & 0.5 & 2.83 & 0.38 \\
\hline \multicolumn{9}{|l|}{ Power } \\
\hline GNS & 1.06 & 0.23 & 1.06 & 0.23 & 2.83 & 0.38 & 2.91 & 0.28 \\
\hline GFL & 1.09 & 0.28 & 1.03 & 0.16 & 1.91 & 0.5 & 1.86 & 0.43 \\
\hline \multicolumn{9}{|l|}{ Distance } \\
\hline GNS & 1.06 & 0.23 & 1.11 & 0.32 & 2.77 & 0.32 & 2.83 & 0.38 \\
\hline GFL & 1.51 & 0.4 & 1.46 & 0.5 & 1.97 & 0.46 & 2.09 & 0.45 \\
\hline
\end{tabular}

10 See Shardakova (2005: 432), for a similar finding in regard to Russian native speakers' assessments. 


\subsection{DCT results}

Table 2 presents the frequencies and percentages of apology strategies used by the two groups in the four situations under examination. Figure 1 presents the frequencies of intensifiers produced by the two groups in the four situations.

Table 2: Distribution of apology strategies by the two groups in the four situations

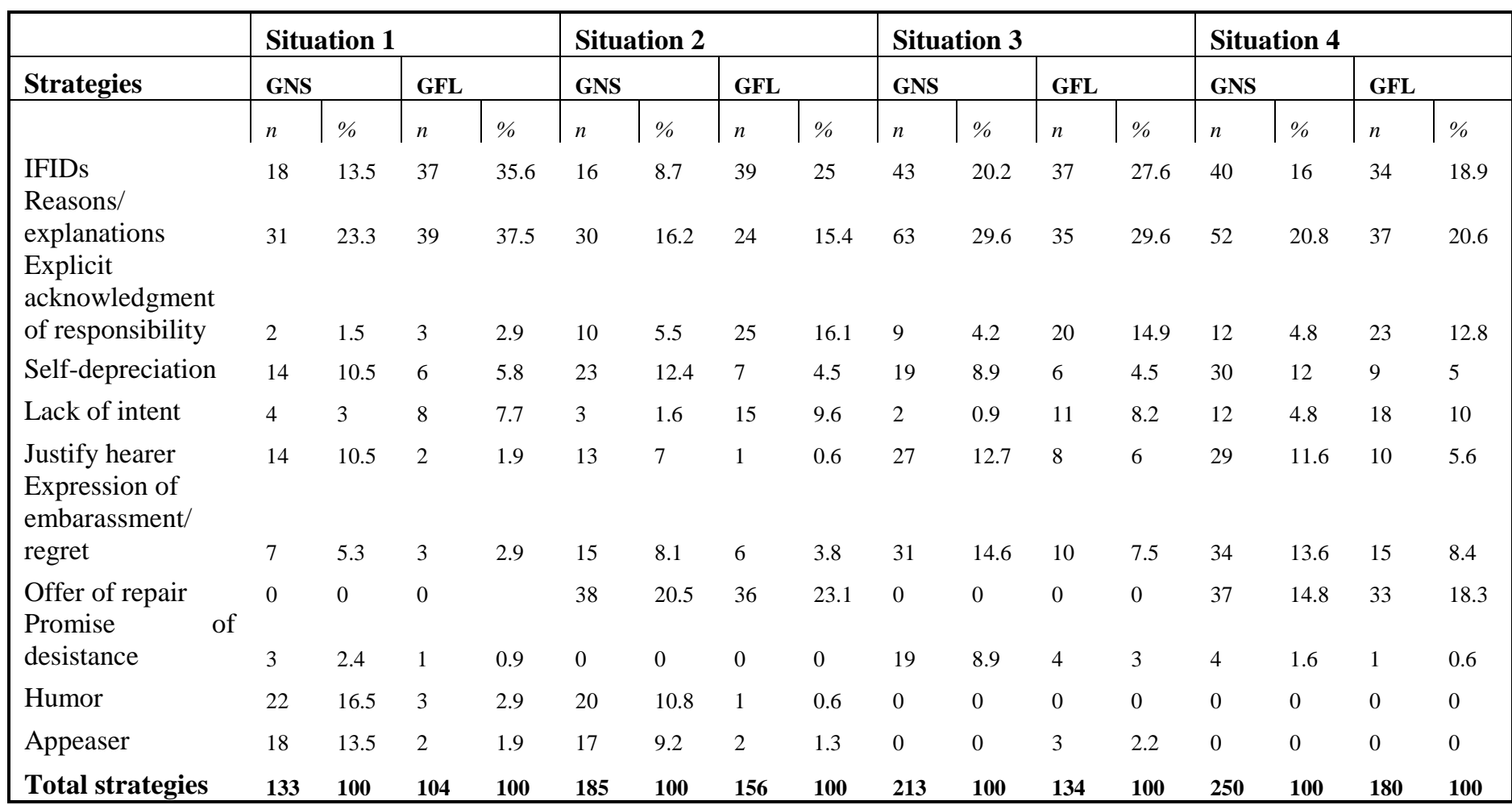




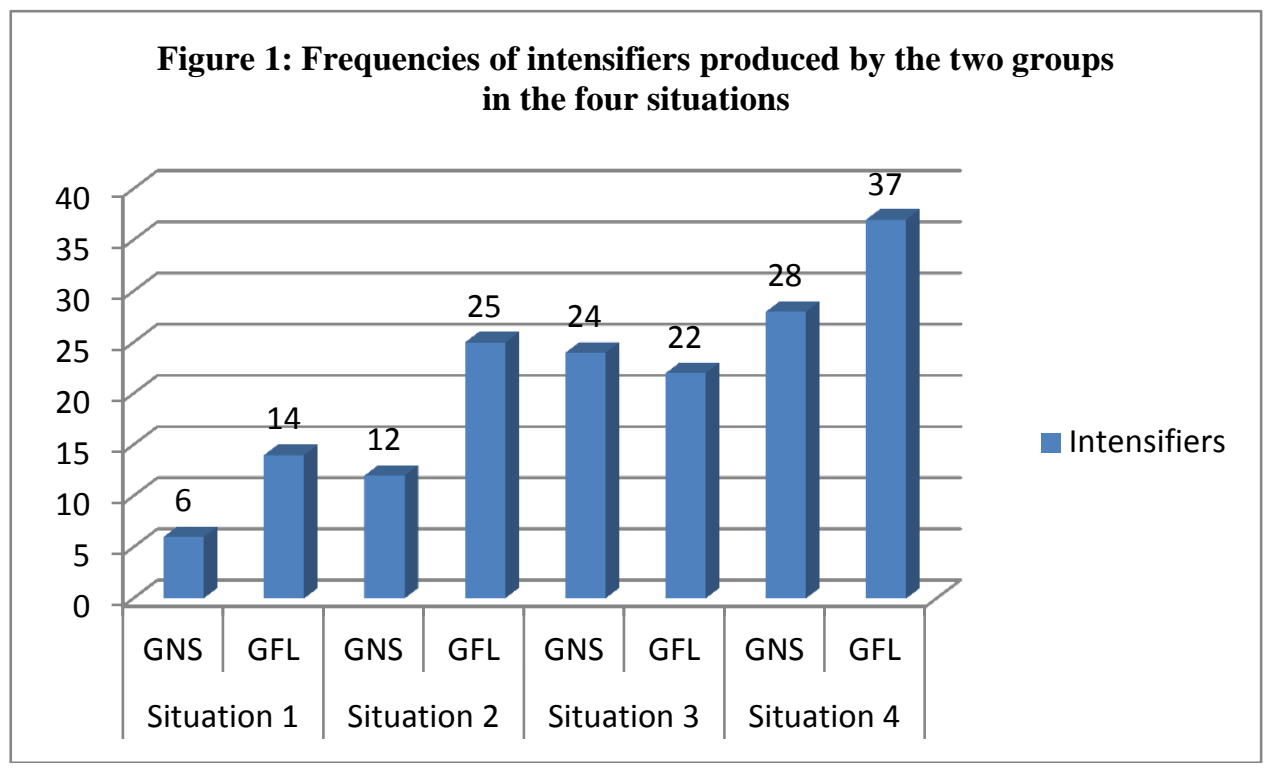

The statistical analysis of the data was carried out using version 19 of the Statistical Package for the Social Sciences. Descriptive statistics were used to compute the frequency of the main strategies and intensifiers for each group across the different situations. The statistical tests used to examine the data were one-way ANOVAs. For all analyses in the study, the alpha level was set at .05. Besides the researcher, the data were coded by a second coder, a Greek female colleague from the Department of Linguistics, Faculty of English Studies. ${ }^{11}$ The second coder's coding coincided with the researcher's in $98 \%$ for apology strategies and $96 \%$ for intensification. The discrepancies noted were discussed by the two coders and a consensus was reached.

The results for each situation are presented in detail in the following subsections (4.2.1-4.2.4).

\subsubsection{Situation 1: Late for appointment with friend}

As shown in Table 2, the native speakers (GNS) used considerably less IFIDs than the learners (GFL) in Situation 1. This difference proved to be statistically significant $(F$ $(1,69)=39.8, \mathrm{p}<0.05, \mathrm{MGNS}=0.37, \mathrm{MGFL}=1.06, \mathrm{SDGNS}=0.49, \mathrm{SDGFL}=0.41)$. The IFIDs used by the native speakers consisted mainly in $\sigma v \gamma \gamma v \omega \dot{\mu} \mu \eta$ ('I am sorry'[lit. forgiveness]) and the informal English form sorry and were hardly ever accompanied by intensifiers (see Figure 1). GFL used $\sigma v \gamma \gamma v \omega ́ \mu \eta$ ('I am sorry') exclusively and more intensifiers than native speakers, although this difference did not turn out to be statistically significant. Nevertheless, they often intensified $\sigma v \gamma \gamma \nu \omega \dot{ } \mu \eta$ ('I am sorry') by means of the adverb $\pi 0 \lambda \dot{v}$ (much, a lot ), which is not a native-like form of intensification in Greek. Specifically, the utterance $\sigma v \gamma \gamma v \omega \dot{\mu \eta} \pi o \lambda \dot{~[l i t . ~ f o r g i v e n e s s ~}$ much] is syntactically incorrect in Greek. Although it is translated as 'I am very sorry', which is perfectly acceptable in English, being a noun $\sigma v \gamma \gamma v \omega ́ \mu \eta$ cannot be qualified by

\footnotetext{
${ }^{11}$ I understand that the coding procedure would perhaps be more reliable if the two coders differed in gender, as suggested by one of the reviewer's, but, unfortunately this was not possible in this case.
} 
the adverb $\pi o \lambda v$. However, this is a very common mistake made by learners of Greek who tend to treat $\sigma v \gamma \gamma v \omega$ ' $\mu \eta$ like $\varepsilon v \chi \alpha \rho \imath \sigma \tau \omega$ ' ('thank you'), which being a verb can very well collocate with the adverb $\pi \circ \lambda \dot{v}$ (Bella 2012: 1933).

Both GNS and GFL participants provided a number of reasons and explanations for their delay. Yet, while GNS often retreated to explanations related to their own personality, which their interlocutor was supposed to be familiar with (e.g. you know me, being late is my hobby, I overslept again, etc.), the learners preferred explanations that had to do almost exclusively with external factors (e.g. heavy traffic, late transportation, strikes, etc.). Furthermore, native speakers employed a "justify hearer" strategy in several instances in this situation. The realization of this strategy in the GNS data consisted almost exclusively in the formulaic expression ó, $\tau \iota \kappa \alpha l v \alpha \pi \varepsilon l \varsigma \varepsilon^{\prime} \chi \varepsilon l \varsigma \delta i \kappa l o$ ('whatever you may say, you will be right'), which was used only by 2 learners in this situation. Nevertheless, what appeared to be most characteristic about the native speakers' behavior in this situation was the use of humor (16.5\%). Moreover, these speakers employed several appeasers $(13.5 \%)$, thus distracting the hearer from the offence (see Blum-Kulka et al. 1989: 234). As shown in Table 2, both these last strategies were practically absent from the GFL participants' performance. Examples (13) coming from the GNS and (4-5) from the GFL data are indicative of the aforementioned differences:

\section{(1) GNS}

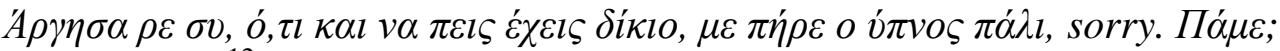

I am late $[\mathrm{re}]^{12}$, whatever you may say you will be right, I overslept again, sorry. Shall we get going?

\section{(2) GNS}

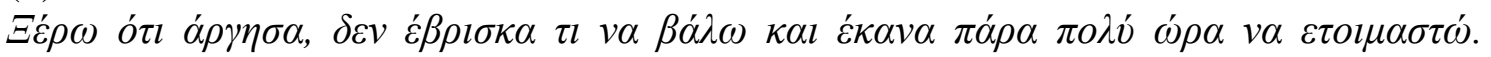

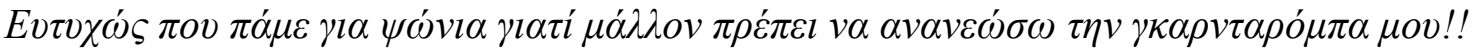
I know I am late I couldn't figure out what to wear and it took me ages to get ready. It's a good thing we are going shopping because it seems I have to renew my wardrobe!!

\section{(3) GNS}

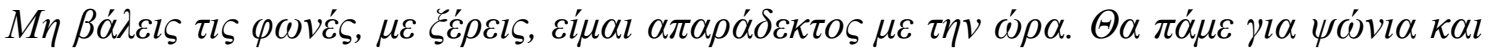

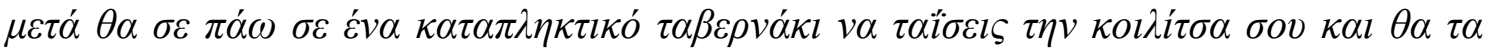
$\xi \varepsilon \chi \alpha \dot{\sigma} \sigma \varepsilon l \varsigma o ́ \lambda \alpha$.

Don't yell at me, you know me, I am impossible with time. We'll go shopping and then I will take you to a great little taverna to feed your tummy and you will forget all about it.

(4) GFL

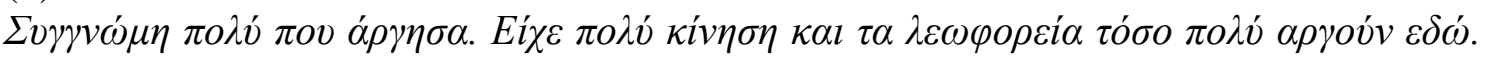

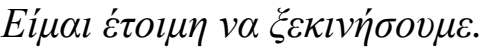

I am very sorry [lit. forgiveness much] I am late. There was a lot of traffic and the buses are so late here. I am ready to go.

\section{(5) GFL}

\footnotetext{
${ }^{12} \rho \varepsilon$ is an untranslatable item expressing solidarity.
} 


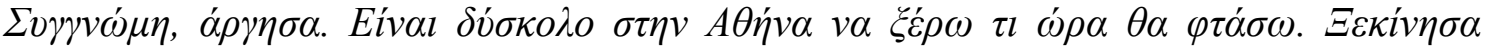

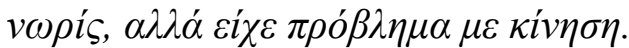

I am sorry, I am late. In Athens it is difficult to know how long it will take. I started early but there were problems with the traffic.

In both (4) and (5) the learners start their contributions with an IFID ( $\sigma v \gamma \gamma \nu \omega \dot{ } \mu \eta$ 'I am sorry') and proceed to provide explanations that attribute their delay to situations related to circumstances common in the Greek context (traffic and late buses in (4) and traffic in Athens in (5)).

In example (1), on the other hand, after the formulaic ó, $\tau l \kappa \alpha l v \alpha \pi \varepsilon l \varsigma$ É $\chi \varepsilon l \varsigma$ díklo (whatever you may say you will be right) the Greek native speaker proceeds to invoke common ground between himself and the interlocutor stating that he overslept "again".

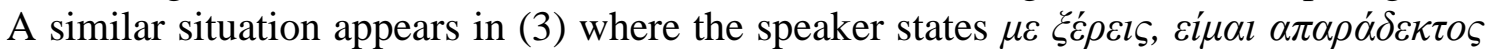
$\mu \varepsilon \tau \eta v \omega ́ \rho \alpha$ ('you know me, I am impossible with time'). What is also worth noting is that, besides being less frequent, the IFIDs used by the GNS in this situation appeared mainly at the end of their contributions. Example (1), where the GNS finishes his apology with the informal IFID sorry is indicative of this tendency. GFL participants, on the other hand, were found to use IFIDs at the beginning of their contributions as indicated in (4) and (5).

Both (2) and (3) are indicative of the native speakers' tendency towards the use of humor and appeasers in this situation. Specifically, in (2) the speaker acknowledges her delay $\xi_{\varepsilon}^{\prime} \rho \omega$ ó $\tau \iota ~ \alpha ́ \rho \gamma \eta \sigma \alpha$ ('I know I am late'), but hardly makes an attempt to justify herself further. Instead she makes a humorous remark, stating that it is a good thing they are going shopping because her wardrobe has to be renewed. Similarly in (3) the speaker combines humor with an appeaser and attempts to distract the hearer from the

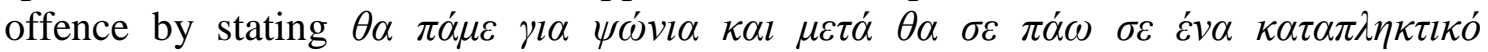

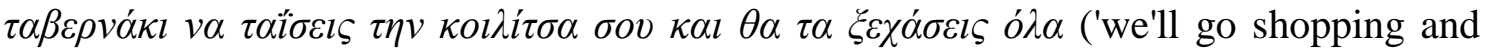
then I will take you to a great little taverna to feed your tummy and you will forget all about it'). As already mentioned, humor and appeasers were hardly ever attested in the learners' performance. The differences regarding the sociopragmatic effects of their presence/absence in the two groups' performance will be discussed in section 5 .

\subsubsection{Situation 2: Breaking friend's DVD player}

In Situation 2, GNS participants employed once more, significantly fewer IFIDs than GFL did $(F(1,69)=42.02, \mathrm{p}<0.05, \mathrm{MGNS}=0.46, \mathrm{MGFL}=1.11, \mathrm{SDGNS}=0.5$, SDGFL=0.79). However, greater variation with respect to the IFID forms was attested in the GNS data.

That is, while the learners relied exclusively on $\sigma v \gamma \gamma v \omega \omega_{\mu \eta}$ ('I am sorry'), the native speakers used $\sigma v \gamma \gamma \nu \omega \dot{\mu} \mu \eta$ ('I am sorry') as well as $\chi i \lambda \iota \alpha \sigma v \gamma \gamma \nu \omega ́ \mu \eta$ ('a thousand apologies' [lit. a thousand forgivenesses]) and the English form sorry in this situation. Once more, the IFIDs used by the GNS in this situation appeared mainly at the end of their contributions (see examples (7) and (9)). In contrast, GFL participants showed a marked preference for initiating their apologies by means of an IFID. Furthermore, GFL participants employed significantly more intensifiers than the GNS participants ( $F$ $(1,69)=16.02, \mathrm{p}<0.05, \mathrm{MGNS}=0.37, \mathrm{MGFL}=1.6, \mathrm{SDGNS}=0.49, \mathrm{SDGFL}=0.5)$. However, their means of intensification deviated from the Greek norm, since they once 
more used adverbials such as $\pi \circ \lambda \dot{v}$ ('much'), $\pi \dot{\alpha} \rho \alpha \pi o \lambda \dot{v}$ ('very much'), $\alpha \lambda \eta \theta \imath v \dot{\alpha}$ ('really'), $\tau \rho о \mu \varepsilon \rho \alpha ́$ ('terribly').

No significant differences were attested in the two groups' performance with respect to the frequencies of reasons/explanations and offer of repair. As shown in Table 2 , both groups used the aforementioned strategies quite frequently in this situation. Nevertheless, significant differences were observed in the use of a number of strategies, i.e. explicit acknowledgment of responsibility, self-depreciation, lack of intent, justify hearer, humor and appeasers. Specifically, while the learners were found to use both acknowledgement of responsibility $(F \quad(1,69)=15.3, \mathrm{p}<0.05$, MGNS $=0.29$, MGFL=0.71, SDGNS=0.45, SDGFL=0.46) and lack of intent $(F(1,69)=12.36, \mathrm{p}<$ 0.05, MGNS=0.09, MGFL=0.43, SDGNS=0.28, SDGFL=0.5) significantly more frequently than the native speakers, self-blame exhibited significantly higher frequencies in the GNS data $(F(1,69)=12.1, \mathrm{p}<0.05$, MGNS $=0.66, \mathrm{MGFL}=0.23$, $\mathrm{SDGNS}=0.49, \mathrm{SDGFL}=0.5$ ). Moreover, humor and appeasers that, as indicated in Table 2 , were, once more, quite frequent in the GNS performance $(10.8 \%$ and $9.2 \%$ respectively), were extremely rare in the GFL data.

The aforementioned differences are highlighted in examples (6-8) and (9-10) coming respectively from the GNS and the GFL data:

(6) GNS

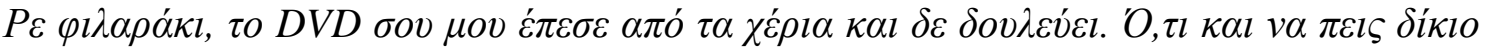

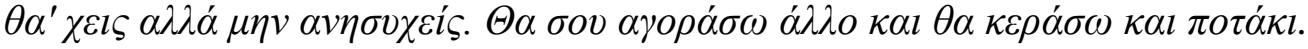

Re friend[diminutive] ('buddy'), your DVD fell from my hands and it doesn't work. Whatever you may say you will be right, but don't worry, I will buy you a new one and I will also buy you a drink[diminutive].

(7) GNS

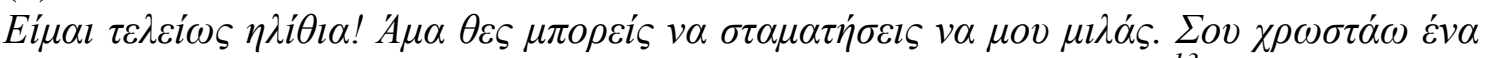

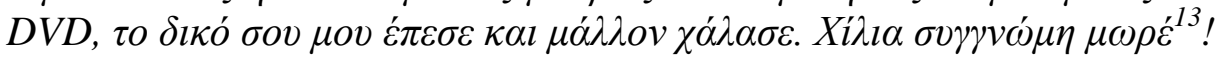

I am a complete idiot! You can stop talking to me if you want. I owe you a new DVD player, yours fell down and it is probably broken. A thousand apologies [more]!

(8) GNS

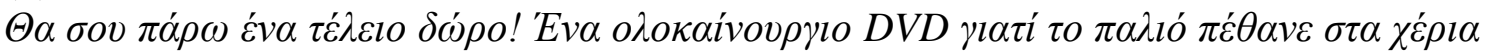

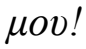

I will get you a great present! A brand new DVD player because your old one died in my hands!

(9) GNS

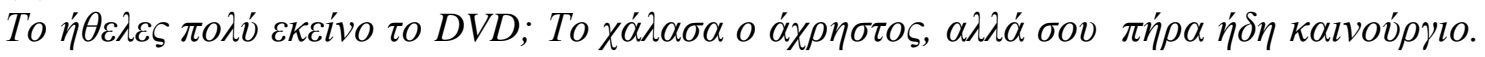
Sorry!

Did you really want that DVD player? Useless me broke it, but I already got you a new one. Sorry.

${ }^{13} \mu \omega \rho \varepsilon ́$ is an untranslatable item expressing solidarity. $\rho \varepsilon$ (see footnote 10) and $\mu \omega \rho \varepsilon ́$ are basically the same item ( $\rho \varepsilon$ being an abbreviated form of $\mu \omega \rho \varepsilon$ ). For the discoursal functions of these items see e.g. Karakhaliou \& Arkhakis (2011). 
(10) GFL

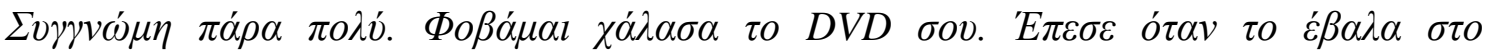

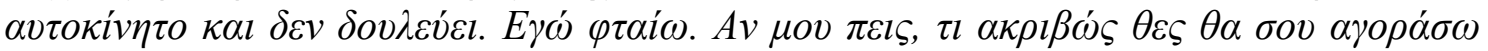
Éva kalvoúpylo.

I am very sorry [lit. forgiveness very much]. I am afraid I broke your DVD player. It fell down when I put it in the car and it doesn't work anymore. It is my fault. If you tell me what exactly you want, I will buy you a new one.

(11) GFL

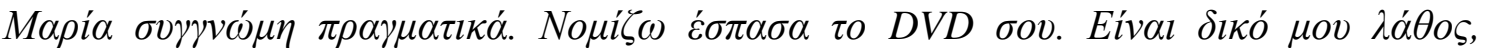

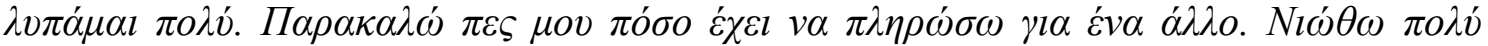
$\dot{\alpha} \sigma \chi \eta \mu \alpha$.

Maria, I am really sorry [lit. forgiveness really]. I think I have broken your DVD player. It is my mistake, I am very sorry. Please tell me how much it costs so I can pay for a new one. I feel really bad.

Example (7) is indicative of the use of the self-depreciation strategy by the GNS in this situation ( $\varepsilon i \mu \alpha \imath \tau \varepsilon \lambda \varepsilon i \omega \varsigma$ $\eta \lambda i \theta l \alpha$ ! 'I am a complete idiot!'), whereas in (8) the selfdepreciation is combined with explicit acknowledgment of responsibility ( $\tau o \chi \alpha \dot{\alpha} \lambda \alpha \sigma \alpha o$ $\alpha \chi \chi \rho \eta \sigma \tau o \varsigma$ 'useless me broke it'). Instances of humor appear in examples (7) ( $\sigma o v$

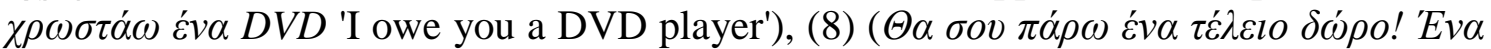

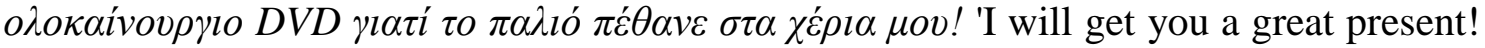
A brand new DVD player because your old one died in my hands!') and (9) ( $\pi o \lambda \dot{~ \varepsilon \kappa \varepsilon i v o ~ \tau o ~ D V D ; ~ ' D i d ~ y o u ~ r e a l l y ~ w a n t ~ t h a t ~ D V D ~ p l a y e r ? '), ~ w h i l e ~ t h e ~ a p p e a s e r ~ i n ~(7) ~}$ ( $\kappa \alpha l \theta \alpha \kappa \varepsilon \rho \alpha ́ \sigma \omega \kappa \alpha l \pi o \tau \alpha ́ \kappa l$ 'and I will also buy you a drink') is typical of the use of this strategy in these speakers' data.

As indicated by examples (10-11) and Table 2, the aforementioned strategies were, once more, absent from the learners' performance. Instead, GFL participants tended to opt for an IFID followed by an explanation and an offer of repair in this situation. Furthermore, the explicit acknowledgements of responsibility in examples

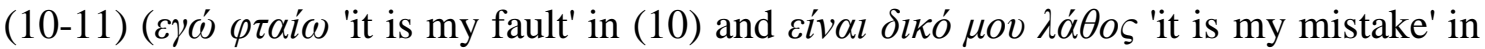
(11)) are indicative of the use of this strategy in these learners' data. Yet, this particular strategy exhibited significantly lower frequencies in the performance of the native speakers in this situation.

\subsubsection{Situation 3: Late for appointment with professor}

The picture with respect to the GNS participants' behavior in Situation 3 was markedly different from the one described for the previous two situations. As shown in Table 2, when interacting with a professor Greek speakers actually employed significantly more IFIDs than the learners $(F \quad(1,69)=4.5, p<0.05, \quad M G N S=1.26, \quad M G F L=1.06$, $\mathrm{SDGNS}=0.5$, SDGFL=0.4). Moreover, their IFIDs exhibited much greater variety and

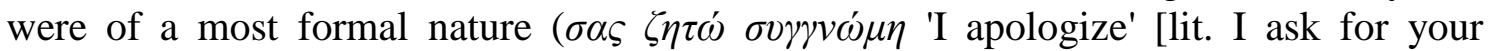
forgiveness], $\mu \varepsilon \sigma v \gamma \chi \omega \rho \varepsilon i \tau \varepsilon \pi \dot{\alpha} \rho \alpha \pi o \lambda \dot{v}$ ( 'I am very sorry' [lit. forgive me [declarative] very much]). In contrast, GFL IFIDs consisted in the use of $\sigma v \gamma \gamma v \omega \dot{ } \mu \eta$ ('I am sorry') and $\lambda v \pi \dot{\alpha} \mu \alpha l$ ('I am sorry' [lit. I am sad]). Furthermore, 6 instances of the verb $\alpha \pi \sigma \lambda o \gamma o v \mu_{\alpha} \alpha$ appeared in the GFL data. Although this verb does exist in Greek and sounds very much 
like the English 'apologize', its meaning in Greek is not 'to apologize' but 'defend oneself' or 'plead' and is mostly used in courts (cf. Symeon 2000: 121).

No statistically significant difference was attested between the two groups in relation to intensification. However, the native speakers were found to use much more intensification in this than in the previous two situations, whereas the learners employed, once again, several adverbials that are not considered appropriate intensifiers in Greek.

Both groups provided a number of reasons/explanations for missing the appointment. However GNS reasons/explanations were considerably more frequent than the ones provided in the previous two situations and were significantly more than the learners' $(F(1,69)=62.57, \mathrm{p}<0.05, \mathrm{MGNS}=1.86, \mathrm{MGFL}=1.06, \mathrm{SDGNS}=0.55$, SDGFL=0.23). Furthermore, an interesting finding in regard to the use of reasons/explanations was of a qualitative nature. Specifically, only 2 native speakers told the truth about the reasons for missing the appointment, i.e. that they had actually forgotten it. The vast majority opted for forged explanations that mainly involved family and health problems. In contrast, the learners markedly chose to tell the truth about missing the appointment. Therefore, their explanations were rather concise and not as elaborate as the ones provided by the GNS. Moreover, it is worth noting that, unlike the native speakers, the learners often proceeded to ask the professor for rescheduling.

As regards the rest of the strategies, GNS exhibited significantly greater frequencies in the use of self-depreciation $(F(1,69)=9.29, \mathrm{p}<0.05$, MGNS $=0.54$, MGFL=0.17, SDGNS=0.6, SDGFL=0.38), expressions of regret $(F(1,69)=20.71, \mathrm{p}<$ $0.05, \mathrm{MGNS}=0.89, \mathrm{MGFL}=0.29, \mathrm{SDGNS}=0.63, \mathrm{SDGFL}=0.45)$ and promise of desistance $(F(1,69)=17.87, \mathrm{p}<0.05, \mathrm{MGNS}=0.54, \mathrm{MGFL}=0.11, \mathrm{SDGNS}=0.5$, SDGFL=0.32). Moreover, they employed rather high frequencies $(12.7 \%)$ of the

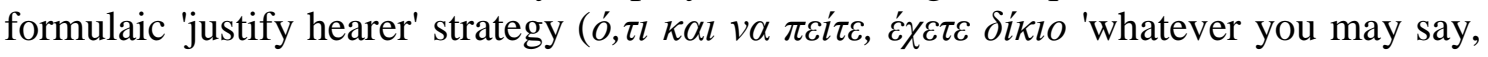
you will be right'). The learners, on the other hand, were found to employ explicit acknowledgment of responsibility with significantly higher frequency than the Greek participants $(F(1,69)=6.81, \mathrm{p}<0.05, \mathrm{MGNS}=0.26$, MGFL=0.57, SDGNS=0.44, SDGFL=0.55). Examples (12) and (13) from the GNS and (14) and (15) from the GFL data are indicative of these differences:

\section{(12) GNS}

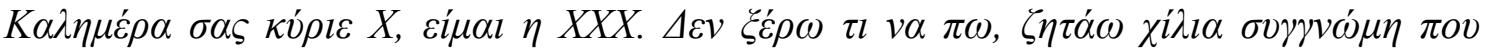

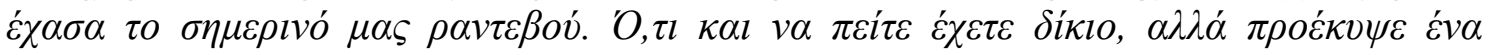

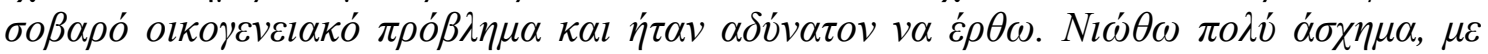

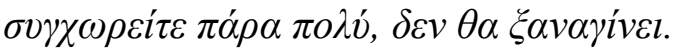

Good morning Mr X, I am XXX. I don't know what to say, a thousand apologies for missing our appointment today. Whatever you may say you will be right, but a serious family problem came up and it was impossible for me to come. I feel really bad, forgive me [very much], it will not happen again.

(13) GNS

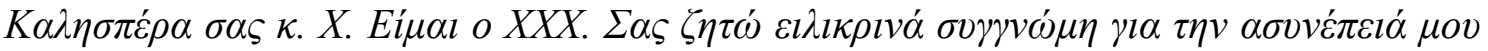

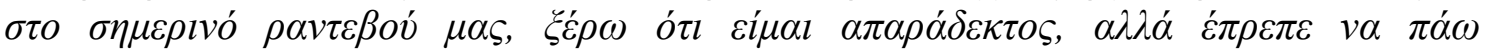




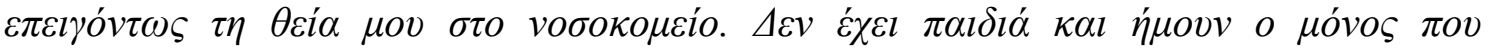

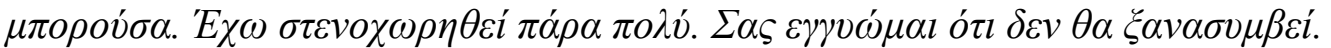

Good afternoon Mr X, I am XXX. I really apologize (lit. I really ask for forgiveness) for my breaking our appointment today, I know I am out of line, but I had to take my aunt to the hospital urgently. She has no children of her own and I am the only one who could do it. I am very upset. I guarantee it will not happen again.

(14) GFL

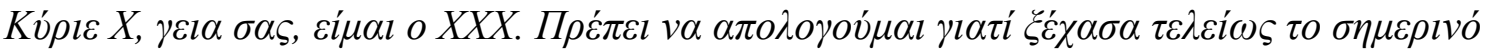

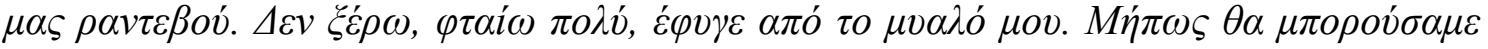

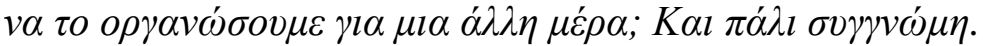

Hello Mr X, I am XXX. I must apologize [lit. I must defend myself] for completely forgetting our appointment today. I don't know, I am very much to blame, it slipped out of my mind. Could we make a new one for some other day? Again, I am sorry.

(15) GFL

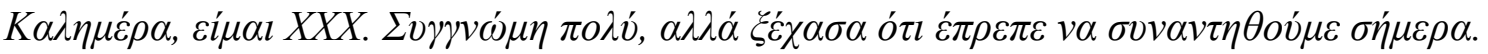

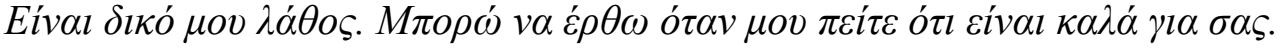

Good morning, I am XXX. I am very sorry [lit. forgiveness much], but I forgot that we were supposed to meet today. It's my fault. I can come whenever you say it would be good for you.

Both (12) and (13) mirror the nature of the reasons/explanations native speakers provided in this situation (family in (12) health and family in (13)). In contrast, as shown in (14) and (15), GFL participants chose to state that they forgot about the appointment and to explicitly acknowledge responsibility ( $\varphi \tau \alpha i \omega \pi \circ \lambda \dot{v}$ ('I am very much

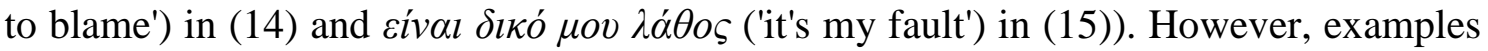
(14) and (15) coming from the learners' data are indicative of the absence of instances of

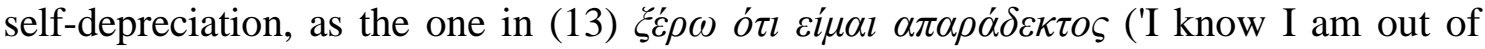
line') and expressions of regret/embarrassment like $v \imath \omega \theta \omega \pi \sigma \lambda \dot{\alpha} \alpha \chi \eta \mu \alpha$ ('I feel really

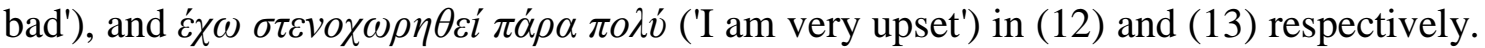
Moreover, while the GNS in (12) and (13) opted for ending their contributions with a promise of desistance, a strategy significantly less frequent in the learners' data. Instead, as indicated by (14) and (15), these learners often chose to end their contributions by asking the professor for rescheduling. The sociopragmatic implications of the differences in the two groups' performance in this situation will be discussed in section 5.

\subsubsection{Situation 4: Destroying professor's book}

In this situation the two groups' behavior with respect to the use of IFIDs was very similar to that of the previous situation (Situation 3). That is, both groups used numerous IFIDs, although GNS employed significantly more than the learners $(F$ $(1,69)=4.81, \mathrm{p}<0.05, \mathrm{MGNS}=1.14, \mathrm{MGFL}=0.97, \mathrm{SDGNS}=0.43, \mathrm{SDGFL}=0.16)$. Moreover, once more, the GNS participants' IFIDs exhibited greater variety than the learners', whereas the learners employed several non-native like IFIDs, similar to the ones discussed in 4.2.3. A statistically significant difference was also observed in regard 
to intensification, with GFL using more intensifiers than GNS $(F(1,69)=4.26, \mathrm{p}<0.05$, MGNS=0.8, MGFL=1.03, SDGNS=0.47, SDGFL=0.45).

In this situation, GFL were found to use significantly more expressions of explicit acknowledgment of responsibility $(F(1,69)=4.94$, p $<0.05$, MGNS=0.34, MGFL=0.66, SDGNS=0.59, SDGFL=0.58), but to lag far behind native speakers in the use of reasons/explanations $(F \quad(1,69)=13.14, \quad \mathrm{p}<\quad 0.05, \quad \mathrm{MGNS}=1.49, \quad$ MGFL=1.06, SDGNS $=0.6$, SDGFL $=0.33)$, self-depreciation $(F(1,69)=28.61, \mathrm{p}<0.05$, MGNS $=0.86$, MGFL=0.2, SDGNS=0.43, SDGFL=0.5), and expressions of regret $(F(1,69)=19.12, \mathrm{p}<$ 0.05 , MGNS=0.94, MGFL=0.43, SDGNS=0.41, SDGFL=0.55).

No statistically significant difference was attested between the two groups in regard to the frequencies of offer of repair, with both groups exhibiting equally high frequencies of this strategy. Examples $(16-17)$ and (18-19) are indicative of the GNS and the learners' behavior respectively in this situation.

(16) GNS

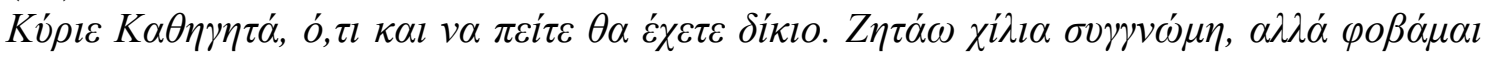

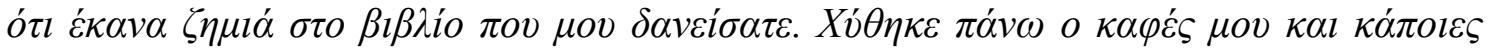

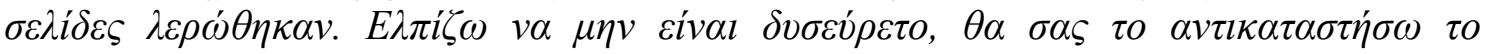

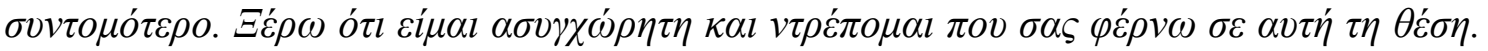

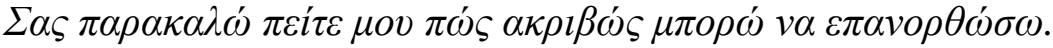

Professor, whatever you may say you will be right. [I ask for] a thousand apologies, but I am afraid I damaged the book you lent me. I spilt my coffee and ruined some pages. I hope it is not rare, I will replace it for you as soon as possible. I know I am unforgivable and I am ashamed for putting you in this position. Please tell me exactly how I can make it up for you.

\section{(17) GNS}

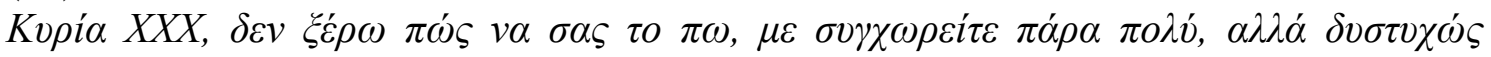

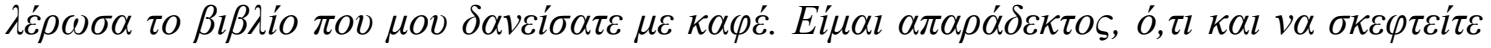

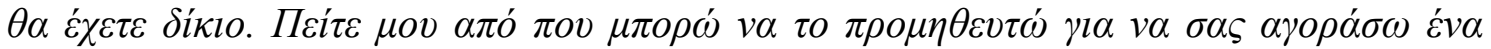

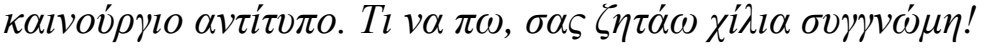

Mrs XXX, I don't know how to tell you, I am very sorry, but unfortunately I stained the book you lent me with coffee. I am inexcusable, whatever you think about me you will be right. Tell me where I can find it, so that I can get a new copy for you. What can I say, I apologize a thousand times!

(18) GFL

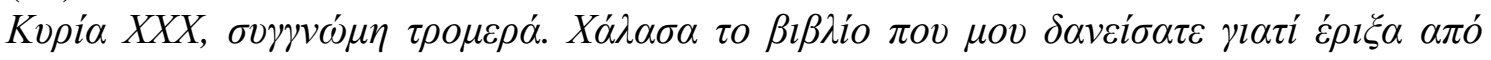

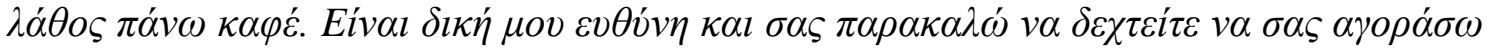

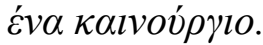

Mrs XXX, I am terribly sorry [lit. forgiveness terribly]. I damaged the book you lent me because I spilt coffee on it by accident. It is my responsibility. Please allow me to buy you a new one.

(19) GFL 


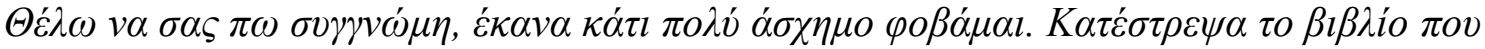

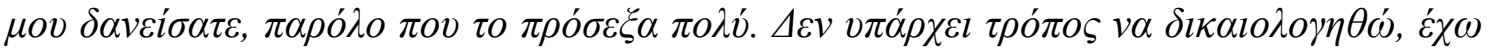

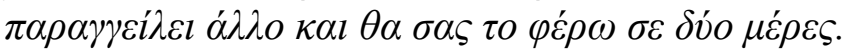

I want to say I am sorry, I did something very wrong, I am afraid. I ruined the book you lent me, although I was very careful. There is no excuse, I have already ordered a new one and I will bring it to you in a couple of days.

As shown in the examples, both groups' participants apologized explicitly, explained the situation and offered repair.

Examples (16) and (17) are typical of the way native speakers employed the

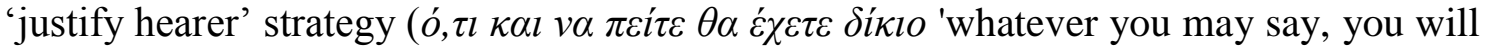

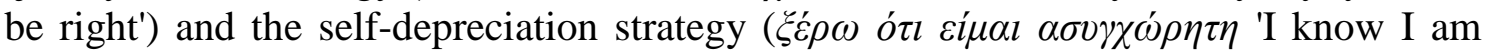

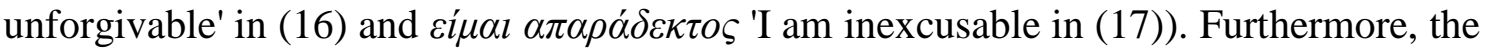
utterance $v \tau \rho \varepsilon \dot{\pi} \pi \circ \mu \alpha l \pi o v \sigma \alpha \varsigma \varphi \varepsilon \dot{\varepsilon} \rho \omega \sigma \varepsilon \alpha v \tau \eta^{\prime} \tau \eta \theta \dot{\varepsilon} \sigma \eta$ 'I am ashamed for putting you in this position' in (16) is indicative of the various ways in which NSs expressed their embarrassment/regret. Instead of using these strategies, the learners were found, once more, to retreat to expressions of explicit acknowledgment of responsibility such as the

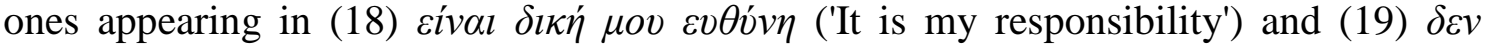

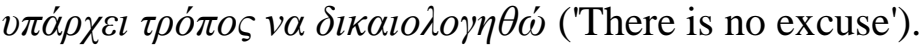

Having presented the most striking quantitative and qualitative differences attested in the two groups' production data, I will turn now to the analysis of the participants' verbal report results.

\subsection{Verbal report results}

In terms of their verbal reports, native speakers were particularly emphatic about the differences between Situations 1 and 2, on the one hand, and 3 and 4, on the other. They stated that the latter were exceptionally 'embarrassing' due to the nature of the professorstudent relationship and, therefore, they believed they had to be 'extra polite' in these situations. ${ }^{14}$

\section{GNS\#4 on Situation 3}

"Missing such an appointment is really bad! How can you make up for that, a professor is not a friend, it's not like that one (pointing at his answer to situation 1). You have to be really careful, very polite, to show her that you really feel bad about this".

They also claimed that it was important for them to show that the occurrences reported in these situations were 'accidental', i.e. not a permanent behavioral feature and to express their respect to their professor.

GNS\#9 on Situation 3

"I felt I had to show him (the professor) that this just happened once. I am not like that in general, not appearing for my work. He will think, what kind of person is this? [...]"

GNS\# 13 on Situation 4

\footnotetext{
${ }^{14}$ Due to space limitations, I provide only the English translations of the participants' answers, which were in Greek.
} 
"Oh, I felt really bad with this one. This is a disaster! Destroying you professor's book! I felt I had to do anything to make up for it. I mean it sounds stupid, a student spilling the coffee all over a borrowed book. I don't know if I would be able to trust this student again."

To the question 'why did you lie about missing the appointment with your professor?', the native speakers stated that this choice had to do with their self-image, as well as their respect towards the professor:

GNS\#12 on Situation 3

"I had to lie! What was I supposed to say, 'oh, sorry, I forgot about it'?. He would think I am totally insensitive and that I don't have any respect for him".

GNS\#15 on Situation 3

"Come on, you don't forget about an appointment with a professor. I mean, you do forget, but you don't admit it. It would reflect really badly on you".

Nevertheless, these speakers admitted that they did not have the same concerns about Situations 1 and 2.

GNS\#6 on Situation 1

"[...] Standing up people happens all the time. It's not nice, but it's not very serious when the other person is your friend. You just say something...I don't know... nice... and get over with it."

GNS\#1 on Situation 2

"This is a problem. But it is repairable. I mean you just buy a new DVD player. It's not like it is a stranger, like the one where I destroyed the professor's book here (pointing at situation 4)."

Learners, on the other hand, stated that they found Situations 1 and 2 more difficult and noted that they were not particularly satisfied with their answers to these situations.

GFL\#19 on Situation 1

"Well, this was difficult for me. I know it's polite but I am not sure it sounds OK in Greek. I think Greeks make more fuss about such things...say more...I can't be sure".

GFL\#7 on Situation 2

"I really didn't know what to say here. Well, obviously you apologize and you offer to buy an new machine, but I feel something is missing here...I don't know".

In the case of Situations 3 and 4 they claimed that they felt they had to be more formal because they were speaking to a professor.

GFL\#5 on Situation 4 
"I had to be a bit more polite here, because she is not a friend of mine. I don't know...more formal. I think I did OK, I mean you have to apologize profusely don't you? It can't be that different in Greek."

Moreover, in the case of Situation 3, many of the learners noted that it was important for them to 'clear the ground' in order to be able to ask for rescheduling the appointment.

GFL\#10 on Situation 3

"It was important to show him I respected him. We will have to work together and I need to make a new appointment. So I had to apologize, it's only logical".

Their primary unease in Situation 4 concerned the probability of being unable to replace the book in order to eliminate the imposition as much as possible.

GFL\#3 on Situation 4

"I think that was the worst of all (referring to the situations). You know, sometimes these books are rare and if it turns out it's irreplaceable, you put yourself in a really difficult situation. An apology is not enough, if you can't get a new book you still owe him (the professor)."

To sum up, the following general conclusions can be drawn from the participants' verbal reports:

1. Both groups noticed the social parameters of the situations under examination and were concerned about employing appropriate pragmalinguistic means.

3. NNSs expressed explicit concern about being able to sound friendly and polite at the same time in Greek.

4. NSs seem to count on the solidarity existing between friends much more than the NNSs.

5. Although no mention was made, of course, of the terms 'positive' or 'negative' face, both groups appeared to focus on different aspects of the interlocutors' face at the same time. However, NSs' statements indicated a greater focus on solidarity (both interlocutors' positive face) when apologizing to a friend and their own positive face when apologizing to a professor. NNSs, on the other hand, made more frequent reference to the rights and freedom of action of their interlocutors' in the familiarity situations and showed more concern for their own and the interlocutor's negative face needs in the formal situations than the NSs.

\section{Discussion}

This section discusses the findings presented in section 4. Subsection 5.1 focuses on the differences displayed by the two groups under examination in the familiarity (5.1.1) and non-familiarity situations (5.1.2) and relates them to the two groups' perceptions of the contextual parameters involved in these situations. Subsection 5.2 discusses issues of transfer and development that arise from the learners' data. 


\subsection{Differences in strategy use}

\subsubsection{Situations $1 \& 2(-P,-D)$}

As mentioned in the Results section, NSs used relatively few IFIDs in both familiarity situations. This is consistent with the solidarity politeness orientation of Greek society. According to Sifianou (1992: 42), Greeks "find no obvious reason for apologizing, unless for something they conceive of as being very serious". I will slightly rephrase this argument to claim that it is not that Greeks do not in fact apologize for light offences, but that explicit IFIDs are not their preferred means to do so. Rather, explicit IFIDs appear to be saved for offences that Greek speakers conceive as very serious. As shown by the severity assessment test and the verbal reports, offences towards friends, at least the ones involved in Situations 1 and 2, are not perceived as particularly severe by the NSs of the study. Furthermore, in the few instances that IFIDs are actually used in their data, a marked preference is exhibited for the English word "sorry". This form, which has initially made its appearance in the code of younger generations, is perceived as extremely informal, thus eliminating any distance effect from the speakers' production. ${ }^{15}$ However, they often recognized that their addressee deserved an apology by resorting to a 'justify the hearer' strategy, which is formulaic and unique in the GNS data, i.e. $o$, $\tau l \kappa \alpha l v \alpha \pi \varepsilon l \varsigma \varepsilon^{\prime} \chi \varepsilon l \varsigma \delta i \kappa l o$ ('whatever you may say you will be right') (cf. Symeon 2000). The absence of this particular formula from the learners' production should probably be attributed to their FL status which provides them with very limited opportunity for exposure to naturally occurring every-day Greek interaction, that would allow them to notice the formula and incorporate it to their interlanguage.

As shown in the Results section, what was most characteristic about the native speakers' performance in both familiarity situations was the highly frequent use of humor. This verifies views according to which in Greek society, language is very often seen as a form of play (Antonopoulou \& Sifianou 2003; Hirschon 1992; Mackridge 1992). Discussing the role of humor in Greek telephone call openings, Antonopoulou \& Sifianou (2003) allude to Brown and Levinson's politeness theory which views joking as a means of emphasizing shared background and attenuating face-threatening acts. Against this backdrop, these researchers consider humor as a solidarity-building strategy in friendly interactions in Greek. In the two familiarity situations under examination, apologizers seem to employ humor in order to indicate that good relations, common ground and the spirit of solidarity continue to pertain in the interlocutors' relationship, despite the offence. In this case, humor can be also seen as an indirect realization of the "be optimistic" strategy which, according to Brown and Levinson (1987: 126) reflects "the most dramatic difference between positive-politeness and negative-politeness ways of doing FTAs". That is, besides the solidarity effect mentioned above, the use of humor in these apologies seems to reflect the NSs' conviction that the offence will be considered 'light' not only by themselves but also by the offended parties.

A further characteristic of the GNS production in the familiarity situations was the use of appeasers. This strategy can be considered an output of Brown \& Levinson's "offer, promise" (1987: 125) or "give gifts to H" (1987: 129) positive politeness strategies and can be seen as a solidarity-building device emphasizing the communal

\footnotetext{
${ }^{15}$ See also Terkourafi (2011) for the functions of the borrowed marker sorry in Cypriot Greek.
} 
spirit between the interlocutors. A notable finding is that Greek speakers do not seem to hesitate to impose upon the hearer and threaten her/his negative face by presupposing his/her cooperation in the "appeasing" act (see e.g. example (3)).

Finally, in both familiarity situations, but especially in Situation 2, NSs employed various forms of particularly exaggerated self-depreciation. That is, they did not hesitate to directly threaten their own positive face in order for their apology to be more effective.

As shown in section 4, many of the above strategies were completely absent from the learners' production in the familiarity situations. Specifically, humor, appeasers and self-depreciation hardly made an appearance in these learners' data. Their apologies consisted mainly in IFIDs and reasons/explanations for their delay. The frequent use of IFIDs comes hardly as a surprise, since the relevant research has more than often showed that IFIDs are a most preferred device by English speakers (see e.g. Márquez Reiter 2000; Ogiermann 2009; Olshtain \& Cohen 1989; Shardakova 2005; Symeon 2000), irrespective of the contextual parameters of power and social distance. Therefore, the abundant use of IFIDs in the familiarity situations by these learners can be relatively safely viewed as an instance of pragmatic transfer. Nevertheless, although the use of IFIDs, especially at the beginning of the learners' contributions (as is often the case), guarantees a politeness effect, the present research revealed that Greek native speakers avoid using IFIDs at the beginning of their contributions when apologizing to friends. This is consistent with Symeon's (2000) finding that Greeks tended to pre-pose positive politeness strategies in their apologies, whereas English speakers exhibited the opposite tendency, pre-posing negative politeness strategies and IFIDs. Therefore, the learners' pre-posing of IFIDs in these familiarity situations could be perceived as "cold" and impersonal by the NSs. This effect could be further reinforced by the observed absence of the various native-like solidarity-building strategies in the learners' production.

Furthermore, it was observed that learners used considerably more intensifiers in Situation 2. Since a similar behavior on their part was also observed in Situation 4, it could be suggested that in their data, intensification correlates with severity of offence. That is, the learners tended to use more intensification in the situations that they conceived as more severe, i.e. the ones involving property damage.

As was shown in the Results section, no significant differences were observed between the two groups in the use of reasons/explanations and offer of repair. It was pointed out, however, that, unlike learners, native speakers, showed a marked tendency towards invoking explanations that emphasized common ground between the interlocutors, thus serving positive politeness considerations.

\subsubsection{Situations $3 \& 4(+P .+D)$}

A different picture emerged in Situations 3 and $4(+\mathrm{P},+\mathrm{D})$ that involved apologizing to a professor. As shown by the assessment questionnaire and the verbal report data, the Greek participants not only considered offences towards a professor as more severe than those towards a friend, but they also judged the relationship with the professor as considerably more distant than learners did. This is consistent with Bella \& Sifianou's (2012: 91) contention that Greek students "construe their relationship with teachers as socially distant and status-incongruent". That is, they consider such relationships as 
highly asymmetrical, with professors having power as faculty members in a society, which cultivates power differences and formality in academic contexts (Hirschon 2001).

Moreover, as Bella \& Sifianou (2012: 92) observe, the very large number of students enrolled in any given course and the fact that that attendance is not obligatory are basic characteristics of the Greek University. Therefore, students normally know their teachers but not the other way round, so the assumed social distance is rather high" (Bella \& Sifianou 2012: 92). Against this backdrop, the variety of formal IFIDs that was observed in Greek speakers' data in Situations 3 and 4 is to be expected. That is, unlike England, where relatively informal teacher/student relationships prevail (Bargiela et al. 2002; Bousfield 2008: 94), formality seems to be a basic characteristic of studentprofessor interactions in Greek academic circles (Bella \& Sifianou 2012; Hirschon 2001). Therefore, explicit IFIDs seem to be the expected norm of behavior in a situation which is viewed as highly formal.

Furthermore, an increase in the frequency of reasons/explanations was characteristic of the native speakers' performance in these two formality situations. Thus a positive correlation can be observed between severity of offence, which for these speakers correlates with power/distance and their need to explain their behavior. As mentioned in the Results section, a very interesting finding with respect to explanations involved the fact that, in their vast majority, the Greek native speakers avoided telling the truth about the reasons for missing their appointment, i.e. that they had actually forgotten about it. Instead, they opted for forged explanations that mainly involved family and health problems, which are generally considered legitimate and acceptable excuses for transgressions in Greek society. This choice is very clearly explained in their verbal reports: telling the truth about forgetting the appointment could be conceived by the professor as an insult, since it would be interpreted as indifference and disrespect. Moreover, it would damage their own image as responsible and reliable students, i.e. it would cause injury to their positive aspect of face. Furthermore, despite the perceived formality of the situations under examination, Greek speakers were found not to hesitate to provide their interlocutor with many details of a personal nature in their explanations. As Symeon (2000: 131) confirms the positive politeness orientation of Greek society allows for personal information to be "easily exchanged among people even if their relationship is not that intimate". This is consistent with Ogiermann's (2009: 178) contention that "effusive explanations providing the hearer with information enabling him or her to understand the speaker's position [...] are [...] characteristic of a positive politeness culture".

A further characteristic of the native speakers' production in Situation 3 was the frequent use of the "promise of desistance" strategy. The classification of the act of promise is not particularly straightforward in Brown and Levinson's politeness theory. Brown and Levinson (1987: 125) classify promises as acts threatening the addressee's negative face "predicating some positive future act of $\mathrm{S}$ toward $\mathrm{H}$, and in so doing put some pressure on $H$ to accept or reject them, and possibly to incur a debt" (1987: 66). However, they proceed to claim that promises can be considered positive politeness strategies that "demonstrate S's good intentions in satisfying H's positive-face wants". Yet, I suggest that in the context of Situation 3 neither of the above seems to be the primary function of the act of promise of desistance. Specifically, I claim that, when used by these NSs in this particular situation, this strategy is consistent with their effort to re-establish their image as reliable individuals, i.e. to protect their own positive aspect 
of face. This is reinforced by their verbal reports where they stressed that they were eager to pass the message that unreliability was not a permanent feature of their personalities.

Although GFL production shared some of the strategies also used by GNS participants in this situation, there were important qualitative and quantitative differences. Specifically, although the learners also used many explicit IFIDs, they mainly relied on $\sigma v \gamma \gamma v \omega ́ \mu \eta$ ('I am sorry') and $\lambda v \pi \alpha ́ \mu \alpha l$ ('I am sorry') often intensified by various forms of non-native like or transferred intensification (e.g. $\sigma v \gamma \gamma \nu \omega ́ \mu \eta \tau \rho о \mu \varepsilon \rho \alpha ́$ [lit. forgiveness terribly] 'I am terribly sorry'). This is probably indicative of a limited repertoire of pragmalinguistic means which does not include many of the IFIDs and intensification devices that NSs seem to employ in both Situations 3 and 4.

Moreover, contrary to the native speakers, these learners opted for telling the truth about missing the appointment in Situation 3. Therefore, their explanations were rather concise and not as elaborate as the ones provided by the NSs. It is possible then that both the content and the length of their explanations in this situation could be perceived as inadequate by the Greek professor. Another feature of the NNSs' production that reflects the different perception of this situation when compared with native speakers was that these learners did not hesitate to ask for rescheduling, which would of course be at the professor's convenience. Therefore, they did not hesitate to claim their assumed rights but at the same time they protected their interlocutors negative face. Emphasizing that the appointment could be rescheduled at the professor's convenience, implied taking responsibility for the offence and indicated that they took their interlocutors' negative face needs into consideration. In contrast, only a very limited number of native speakers asked for rescheduling, avoiding thus further imposition on their professors and, at the same time, protecting their own positive face.

Besides the explicit IFIDs employed by both groups in Situation 4 and the marked differences between them discussed above, both GNS and GFL employed reasons/explanations and offers of repair in this situation. However, as was also the case in Situation 3, the native speakers used increased frequencies of reasons/explanations in this situation and overrated the learners in this respect. What was also observed was a marked preference by GNS for expressions of regret and self-depreciation. In contrast, GFL opted for explicit acknowledgement of responsibility and expressions of lack of intent in this situation. Expressions of regret and self-depreciation were considerably less frequent in their performance. This difference can be seen as reflecting the different concerns for face-protection and enhancement that are characteristic of the participant groups. Comparing Greek and English apologies, Symeon (2000) has found that acknowledgement of responsibility is more common in her English data, while expressions of regret are mostly preferred by Greeks, irrespective of the power and distance parameters of the situations in which apologies appear. Symeon (2000: 73) claims that acknowledgement of responsibility is more closely related to the needs of the negative aspect of the interlocutors' face, since it allows the apologizer to show his respect towards the offended party and at the same time to free himself/herself from the burden of the offence. On the other hand, she sees expressions of regret as reflective of the emotional character of apologies and relates them to the interlocutors' positive face needs, since "through regret the apologizer expresses his psychological suffering because of his involvement in the offensive act and wants to communicate these negative emotions he experiences to the addressee" (Symeon 2000: 73). Therefore, expressions of regret appear to aim at the protection of both interlocutors' positive face. 


\section{2. Transfer and development}

It is not always clear which of the features of these learners' behavior are a result of transfer. Both the assessment questionnaire and their verbal reports indicate that the two groups hold different cultural beliefs about the situations under examination and some of these beliefs are indeed reflected in the data. The extensive use of IFIDs in the familiarity situations and the learners' comparatively greater readiness to explicitly acknowledge responsibility could be considered, therefore, instances of negative transfer from their native language (English).

Moreover, certain IFIDs and intensification tokens found in the learners' data can be regarded as the result of negative transfer from English. The non-native like use of

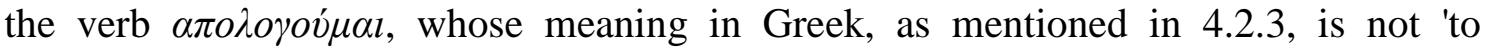
apologize' but 'defend oneself' or 'plead', as well as the use of intensifiers such as,

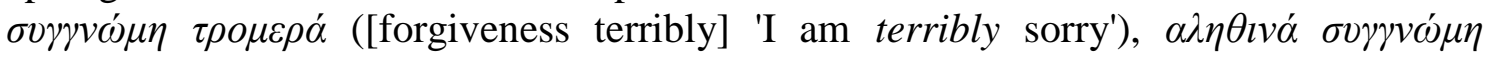
([forgiveness really] 'I am really sorry'), which are not appropriate forms of apology intensification in Greek, are indicative examples of such transferred tokens.

Certain features of the learners' linguistic behavior towards the professor could also be viewed as results of transfer. Both the assessment questionnaire and the verbal reports make clear that these learners view their relationships with their professors as more equal than native speakers do. This licenses them to be more straightforward as indicated by their inclination to tell the truth about missing the appointment with the professor and to ask for rescheduling, strategies that NSs were found to disprefer. It can also explain, to a certain extent, their abstinence from the promise of desistance strategy, which was frequent in the NSs' data in Situation 3. Furthermore, this abstinence could be considered a means of protecting their own negative face, consistent with their native negative face-protection orientation. This orientation, however, is more clearly reflected in the learners' reports explaining their purposes for apologizing than in the data itself. This holds particularly true in the case of Situation 4. The verbal reports about this situation generally revealed that certain strategies used by both groups with similar frequencies, such as the offer of repair strategy, were often aimed to different goals. That is, the NSs seemed to use this strategy mainly in the direction of re-establishing their image as responsible individuals, i.e. protecting their own positive face, whereas NNSs often highlighted the professor's right to reacquire her/his property.

What is of particular interest, however, especially in relation to the familiarity situations, is not what the learners actually do, but what they don't do, when compared to the NSs. It was shown that NSs view their relationship with friends as less distant than the learners. It was also shown that in the familiarity situations NSs employ several solidarity building strategies, such as humor and self-depreciation. Although the scarcity of these strategies in the learners' data could also be attributed to transfer, I believe that in this case the situation is not clear. It has been shown that Greek learners in general face more difficulties in handling informal situations than formal ones (Bella 2012a, 2012b). Moreover, strategies like humorous remarks and expressions of selfdepreciation, being culturally specific, require a great deal of sociopragmatic competence. In addition, these mechanisms appear more often in everyday informal 
interactions, that is, they form part of a type of input to which foreign language learners, like the ones in this study, are rarely exposed. Therefore, not employing certain nativelike strategies may very well be an indication of inadequate sociopragmatic development and not necessarily transfer. This assumption is reinforced by the absence of formulas from their production, like the whatever you may say, you will be right formula, which was extensively used by native speakers as a realization of the 'justify hearer' strategy, as well as their rather limited repertoire of IFID formulas. The lack of such formulas as well as of other native-like strategies can also be attributed to the inadequate sociopragmatic input that these learners are exposed to. That is, as foreign language learners, these speakers may do not have adequate opportunities for social contact with native speakers. Moreover, previous research has pointed out that textbooks for teaching Greek as a second/foreign language, which are the main source of input for these learners, provide very limited information on the adequate expression of various speech acts (see e.g. Bella 2012b), thus verifying Bardovi-Harlig's contention that "in general, textbooks cannot be counted on as a reliable source of pragmatic input for classroom language learners"' (Bardovi-Harlig 2001: 25), (cf. Angouri 2010: 373).

It is possible that instances of transfer as opposed to development inadequacies could have been more clearly discerned, if this research was not subject to one particular limitation, i.e. the lack of English native speakers' data on the situations under examination. Although this limitation was compensated for, at least partially, by the abundant research on English apologies, further research is needed, in order for safer conclusions to be reached with regard to the issues raised in this paper. Future research could also benefit from natural data, in order for the DCT potential limitations to be overcome, and should focus on apologies of Greek learners' from different linguistic backgrounds that will enable interlanguage comparisons.

\section{Conclusions}

This study focused on apologies performed by Greek native speakers and advanced FL English learners of Greek in two informal and two formal situations. The research focus was on the differences between the two groups of participants in terms of their assessments of the contextual parameters of the apology situations under examination as well as in terms of strategy use.

The results of the study revealed that significant differences do indeed exist between the two groups with regard to their assessment of contextual parameters (severity of offence and power/distance). These assessments were reflected both in the participants' choice of strategies, that were found to differ significantly in several respects, and in their verbal reports. Furthermore, differences in the two groups' politeness orientations were also reflected in the two groups' performance. Specifically, Greek native speakers were found to resort to a far greater number and variety of positive politeness strategies, especially in the familiarity situations (-P, -D). The English learners, on the other hand, were found to transfer negative politeness strategies from their L1, but most importantly to heavily underuse the positive politeness strategies prevailing in the NSs' data.

Moreover, several instances of these advanced learners' behavior were attributed to inadequate sociopragmatic development that was related to their foreign language learner status. Therefore, this research confirms that high levels of grammatical 
competence do not guarantee equally high levels of pragmatic competence (BardoviHarlig 1999: 686). Hence, an obvious implication of this study concerns the need for systematic pragmatic instruction that will help foreign language learners "to acquire the sociocultural strategies used most frequently by NSs" (Félix-Brasdefer 2003: 247).

\section{Appendix: Situations under examination ${ }^{16}$}

1. Late for appointment with friend (-P, -D)

You have an appointment with a close $(\text { Greek })^{17}$ friend of yours to go shopping. You arrive half an hour late.

You say to your friend:

2. Damage friend's DVD player (-P, -D)

You borrowed a close (Greek) friend's DVD player for the weekend. It fell down and does not work.

You say to your friend:

3. Late for appointment with professor $(+\mathrm{P},+\mathrm{D})$

You are a University student at the University of Athens. You had an appointment with one of your professors your relationship with whom is strictly academic (you have only interacted in class and during office hours) to discuss an assignment. You forgot about it completely. When you remember you call him/her.

You say:

4. Damage professor's book $(+\mathrm{P},+\mathrm{D})$

You are a University student at the University of Athens. You borrowed a book you needed for an assignment from one of your professors your relationship with whom is strictly academic (you have only interacted in class and during office hours). You accidentally spilled your coffee on the book and it was destroyed. You go to his/her office.

You say:

\section{References}

Angouri, Jo (2010) Using textbook and real-life data to teach turn taking in business meetings. In Nigel Harwood (ed.), Handbook of teaching materials. Cambridge: Cambridge University Press, pp. 373-395.

\footnotetext{
${ }^{16}$ Due to space limitations, I provide only the English translations of the situation descriptions, which were originally presented in Greek.

${ }^{17}$ The clarification in the parentheses in situations 1 and 2 was only given to the English learners of Greek.
} 
Antonopoulou, Eleni, and Maria Sifianou (2003) Conversational dynamics of humor: The telephone game in Greek. Journal of Pragmatics 35: 741-769.

Bardovi-Harlig, Kathleen (1999) Exploring the interlanguage of interlanguage pragmatics: A research agenda for acquisitional pragmatics. Language Learning 49: 677-713.

Bardovi-Harlig Kathleen, and Zoltan Dörnyei (1998) Do language learners recognize pragmatic violations? Pragmatic versus grammatical awareness in instructed L2 learning. TESOL Quarterly 32: 233262.

Bargiela, Francesca, Corinne Boz, Lily Gokzadge, Abdurrahman Hamza, Sara Mills, and Nino Rukhadze (2002) Ethnocentrism, politeness and naming strategies. Working Papers on the Web 3. http://extra.shu.ac.uk/wpw/politeness/bargiela.htm (accessed 16/2/2008).

Bataineh Fahmi, Ruba, and Rula Fahmi Bataineh (2006) Apology strategies of Jordanian EFL university students. Journal of Pragmatics 38: 1901-1927.

Bella, Spyridoula (2009) Invitations and politeness in Greek: The age variable. Journal of Politeness Research 5: 243-271.

Bella, Spyridoula (2011) Mitigation and politeness in Greek invitation refusals: Effects of length of residence in the target community and intensity of interaction on non-native speakers' performance. Journal of Pragmatics 43: 1718-1740.

Bella, Spyridoula (2012) Pragmatic development in a foreign language: A study of Greek FL requests. Journal of Pragmatics 44: 1917-1947.

Bergman, Marc, and Gabriele Kasper (1993) Perception and performance in native and non-native apology. In Gabriele Kasper, and Shoshana Blum-Kulka (eds.), Interlanguage Pragmatics. Oxford: Oxford University Press, pp. 82-107.

Blum-Kulka, Shoshana, Julianne House, and Gabriele Kasper (1989) Cross-cultural pragmatics: Requests and apologies. Norwood, NJ: Ablex.

Blum-Kulka, Shoshana, and Elite Olshtain (1986) Too many words: Length of utterance and pragmatic failure. Studies in Second Language Acquisition 8: 165-180.

Bousfield, Derek (2008) Impoliteness in Interaction. Amsterdam: John Benjamins Publishing Company.

Brown, Penelope, and Stephen Levinson (1987) Politeness: Some Universals in Language Usage. Cambridge: Cambridge University Press.

Christie, Chris (2005) Editorial. Journal of Politeness Research 1: 1-7.

Cohen, Andrew (1996) Developing the ability to perform speech acts. Studies in Second Language Acquisition 18: 253-267.

Cohen, Andrew, and Elite Olshtain (1981) Developing a measure of socio-cultural competence: The case of apology. Language Learning 31: 113-134.

Cordella, Marisa (1990) Apologizing in Chilean Spanish and Australian English: A cross-cultural perspective. ARAL Series 5: 66-92.

Deutschmann, Mats (2003) Apologizing in British English. Umeå: Umeå Universitet. 
Edmondson, Willis, and Juliane House (1991) Let's Talk and Talk About It. München: Urban \& Schwarzenberg.

Ericsson, Anders, and Herbert Simon (1993) Protocol Analysis. Cambridge MA: The MIT Press.

Farashayian, Atieh (2011) A descriptive-comparative analysis of apology strategies: The case of Iranian EFL and Malaysian ESL University students. English Language Teaching 4: 224-229.

Félix-Brasdefer, César (2003) Declining an invitation: A cross-cultural study of pragmatic strategies in American English and Latin American Spanish. Multilingua 22: 225-255.

Félix-Brasdefer, César (2010) Data collection methods in speech act performance: DCTs, role plays and verbal reports. In A. Martínez-Flor, and E. Usó-Juan (eds.), Speech act performance: Theoretical, empirical and methodological issues. Amsterdam/Philadelphia: John Benjamins Publishing Company, pp. 41-56.

Flores Salgado, Elizabeth (2011) The Pragmatics of Requests and Apologies: Developmental Patterns of Mexican Students. Amsterdam/Philadelphia: John Benjamins Publishing Company.

Fraser, Bruce (1981) On apologizing. In F. Coulmas (ed.), Conversational Routine: Exploration in Standardized Communication Situations and Prepatterned Speech. The Hague: Mouton, pp. 259-272.

García, Carmen (1989) Apologizing in English: Politeness strategies used by native and non-native speakers. Multilingua 8: 3-20.

Gass, Susan, and Noël Houck (1999) Interlanguage refusals: A cross-cultural study of Japanese-English. New York: Mouton de Gruyter.

Goffman, Erving (1971) Relations in Public. New York: Basicbooks.

Hirschon, Renée (1992) Greek adults' verbal play, or, how to train for caution. Journal of Modern Greek Studies 10: 35-56.

House, Juliane (1989) 'Oh, excuse me please...' Apologizing in a foreign language. In Berhard Ketteman, Peter Bierbaumer, Alwin Fill, and Annemarie Karpf (eds.), Englisch als Zweitsprache. Tübingen: Narr., pp. 303-327.

Jourdenais, Renée (2001) Cognition, instruction and protocol analysis. In P. Robinson (ed.), Cognition and Second Language Instruction. Cambridge: Cambridge University Press, pp. 354-375.

Jucker, Andreas (2009) Speech act research between armchair, field and laboratory: The case of compliments. Journal of Pragmatics 41: 1611-1635.

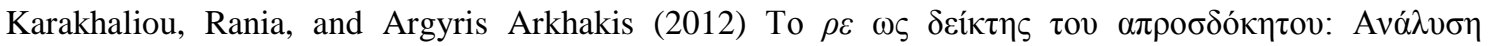

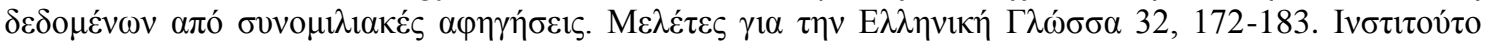

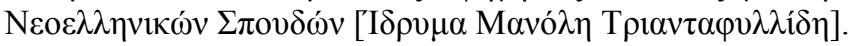

Kasper, Gabriele (1997) The role of pragmatics in language teacher education. In K. Bardovi-Harlig, and B. Hartford (eds.), Beyond methods. New York: McGraw Hill, pp. 113-136.

Kasper, Gabriele (2000) Data collection in pragmatics research. In H. Spencer-Oatey (ed.), Culturally Speaking. London: Continuum, pp. 316-341.

Kasper, Gabriele, and Carsten Roever (2005) Pragmatics in second language learning. In Eli Hinkel (ed.), Handbook of research in second language learning and teaching. Mahwah, NJ: Erlbaum, pp. 317-334.

Leech, Geoffrey (1983) Principles of Pragmatics. London and New York: Longman. 
Locher, Miriam (2006) Polite behavior within relational work: The discursive approach to politeness. Multilingua 25: 249-267.

Mackridge, Peter (1992) Games of power and solidarity-commentary. Journal of Modern Greek Studies 10: 111-120.

Maeshiba, Naoko, Naoko Yoshinaga, Gabriele Kasper, and Steven Ross (1996) Transfer and profieciency in interlanguage apologizing. In S. Gass, and J. Neu (eds.), Speech Acts Across Cultures. Berlin: Mouton de Gruyter, pp. 155-190.

Makri-Tsilipakou, Marianthi (2001) Congratulations and bravo! In A. Bayraktaroğlu, and M. Sifianou (eds.), Linguistic Politeness across Boundaries: The Case of Greek and Turkish. Amsterdam/ Philadelphia: John Benjamins Publishing Company, pp. 137-178.

Márquez Reiter, Rosina (2000) Linguistic Politeness in Britain and Uruguay: A Contrastive Study of Requests and Apologies. Amsterdam: John Benjamins Publishing Company.

Martínez-Flor, Alicia, and Esther Usó-Juan (2006) Learners' use of request modifiers across two University ESP disciplines. Ibérica 12: 23-41.

Ogiermann, Eva (2009) On Apologising in Negative and Positive Politeness Cultures. Amsterdam/Philadelphia: John Benjamins Publishing Company.

Olshtain, Elite (1989) Apologies across cultures. In Sh. Blum-Kulka, J. House, and G. Kasper (eds.), Cross-cultural Pragmatics: Requests and Apologies. New Jersey: Ablex, pp. 155-173.

Owen, Marion (1983) Apologies and Remedial Interchanges: A Study of Language Use in Social Interaction. Berlin: Mouron de Gruyter.

Pavlidou, Theodossia (1994) Contrasting German and Greek politeness and the consequences. Journal of Pragmatics 21: 487-511.

Shardakova, Maria (2005) Intercultural pragmatics in the speech of American L2 learners of Russian: Apologies offered by Americans in Russian. Intercultural Pragmatics 2: 423-451.

Sifianou, Maria (1992) Politeness Phenomena in England and Greece: A Cross-Cultural Perspective. Oxford: Oxford University Press.

Suszyńska, Malgorzata (1999) Apologizing in English, Polish and Hungarian: Different languages, different strategies. Journal of Pragmatics 31: 1053-1065.

Symeon, Despina (2000) Apologies in English and Greek. Unpublished Ph.D. Thesis, University of Athens.

Takahashi, Tomoko, and Leslie Beebe (1987) The development of pragmatic competence by Japanese learners of English. JALT Journal 8: 131-155.

Terkourafi, Marina (2011) Thank you, sorry and please in Cypriot Greek: What happens to politeness markers when they are borrowed across languages? Journal of Pragmatics 43: 218-235.

Thomas, Jenny (1983) Cross-cultural pragmatic failure. Applied Linguistics 4: 91-112.

Trosborg, Anna (1987) Apology strategies in native/non-native English. Journal of Pragmatics 11: 147167.

Trosborg, Anna (1995) Interlanguage Pragmatics: Requests, Complaints and Apologies. Berlin: Mouton de Gruyter. 
Usó-Juan, Esther (2010) Requests: A sociopragmatic approach. In A. Martínez-Flor, and E.

Usó-Juan (eds.), Speech Act Performance: Theoretical, Empirical and Methodological Issues. Amsterdam/Philadelphia: John Benjamins Publishing Company, pp. 237-256.

Usó-Juan, Esther, and Alicia Martínez-Flor (2008) Teaching learners to appropriately mitigate requests. ELT Journal 62: 349-357.

Wolfson, Nessa (1981) Invitations, compliments and the competence of the native speakers. International Journal of Psycholinguistics 25: 7-22.

Woodfield, Helen (2010) What lies beneath?: Verbal report in interlanguage requests in English. Multilingua 29: 1-27.

SPYRIDOULA BELLA is Associate Professor of Linguistics at the University of Athens. Her research interests include pragmatics, second language acquisition and teaching. She has published papers on pragmatics, interlanguage pragmatics and second language acquisition in journals (Journal of Pragmatics, Multilingua, Journal of Politeness Research, Pragmatics) and edited volumes. She is the author of a book on second language acquisition theories and the co-author of two books on language teaching.

Address: University of Athens, Department of Linguistics, 28is Oktovriou 12, 15341 Agia Paraskevi, Greece. E-mail: sbella@phil.uoa.gr 